\title{
II. NATION UND MONARCHISCHE STAATSORDNUNG
}

\author{
1. Paris: Das Zweite Empire zwischen monarchischer Tradition \\ und republikanischer Opposition
}

\subsection{Nation und dynastische Kontinuität: Anläufe zur Traditionsbildung}

Von der Revolution 1848 blieben die Königsstandbilder, die seit der bourbonischen Restauration in Paris entstanden, ebenso unberührt, wie dies knapp zwanzig Jahre später auch für die Zeit der Dritten Republik gelten sollte ${ }^{1}$. Daß öffentliche Denkmäler für Monarchen in Paris ausblieben, war andererseits keinesfalls vorzeitig mit einem abrupten Ende promonarchischer Nationsvorstellungen gleichzusetzen. In der Provinz waren royalistische Voten und Bewegungen weiterhin erkennbar, so daß die Kapitale hier nur bedingt repräsentativ für den landesweiten Diskurs gelten konnte ${ }^{2}$. Nationale Traditionsbildungsversuche des Zweiten Empire verlegten sich statt dessen entweder auf den neuen Empereur selber, oder aber auf das Erste Empire.

In den 1860er Jahren entstanden mehrfach Denkmalprojekte für Napoleon I., die allerdings in keinem Fall auf städtische oder private, sondern in der Regel auf staatliche Initiativen zurückgingen und eher den Charakter von Ergänzungen zur gesamten Repräsentationsarchitektur trugen, um deren Vollendung sich Napoleon III. bemühte. So war etwa ein Reiterdenkmal Napoleons I. auf der Place Napoléon beim Louvre vorgesehen, das im Kontext der Umgestaltung des Tuilerienareals zustandekommen sollte ${ }^{3}$. Ebenso kurzlebig blieb der nicht vom Staat angeordnete, aber wohlwollend unterstützte Versuch, ein Reiterdenkmal Napoleons I. in römischer Kaisertracht zu postieren ${ }^{4}$. Die bereits Mitte der $1850 \mathrm{er}$ Jahre kursierenden Pläne zu weiteren Denkmälern für

Zwar bestanden mit der Chapelle expiatoire oder den Grablegen in St.-Denis durchaus Stätten, die sich für einen Königskult hätten eignen können, indessen waren keine Spuren für eine entsprechende Bewegung in Paris erkennbar.

Vgl. AGulhon, Paris, S. 906f., Anm. 32.

Vgl. Arrêté für das Projekt des Bildhauers Eugène Guillaume vom 26. August 1862, AN $\mathrm{F}^{21} 814$ Dossier: Statue équestre de Napoléon $\mathrm{I}^{\mathrm{er}}$, M. Guillaume sculpteur. Vgl. dazu auch BREsc-Bautier, PINGeOT, Sculptures des jardins du Louvre Bd. 1, S. 113 und Bd. 2, S. $227 \mathrm{f}$

4 Vgl. den undatierten Rapport à son Excellence le Maréchal de France, ministère de la Maison de l'Empereur et des Beaux-Arts vom Directeur des Bâtiments civils, AN F ${ }^{21} 814$ Dossier: Renvoi des Tuileries au Louvre. Statue équestre de François $\mathrm{I}^{\mathrm{er}}$, statue de Napoléon $\mathrm{I}^{\text {er }}$, 1853-1866. Vgl. auch BRESC-BAUTIER, PINGEOT, Sculptures Bd. 2, S. 91-93. 
François $\mathrm{I}^{\mathrm{er} 5}$ in der Cour carrée du Louvre und für Charlemagne ${ }^{6}$ verhartten im Projektstadium, ohne daß Gründe für die unterbliebene Verwirklichung erkennbar wären ${ }^{7}$. Die Errichtung einer Statue Napoleons I. um 1852 auf dem Square Vintimille schließlich entbehrte jeder politischen Motivation. Das stilistisch gewagte Experiment, den Empereur in olympischer Nacktheit darzustellen, wirkte jedenfalls als verfehlter und vielkritisierter Versuch einer Stilisierung zum Helden, die mit der Abtragung und Vernichtung der Statue durch ihren Erbauer ohnedies Episode blieb ${ }^{8}$.

Nach dem Staatsstreich tauchte schließlich ein weiteres Projekt auf, mit dem die Mitglieder eines Komitees beim Napoleon III. nahestehenden Innenminister de Persigny vorstellig wurden. Als überzeugte Parteigänger des erneuerten Empire und vermeintliches Sprachrohr der gesamten Nation forderten sie die Errichtung von 86 Reiterstatuen auf allen zentralen Plätzen in den "principales villes de France ${ }^{9}$. Das Vorhaben glich Plänen für die republikanische Allegorie von 1848/49, indem es, jetzt unter dem Vorzeichen der imperialen Ordnung, auf die visuelle Omnipräsenz des neuen Empereur als plebiszitär erkorene "personne auguste du Souverain qu'elle [la France, H.R.] a librement et unanimement choisi ${ }^{10}{ }^{0}$ zielte und also auch auf die Personifizierung des einmütigen und freien Willens der Nation. Dennoch wurde der ehrgeizige Plan aus nicht mehr erkennbaren Gründen Makulatur; seine Umsetzung mißlang ebenso wie die der erheblich bescheidener dimensionierten Projekte.

Mit zwei schließlich zu Ende gebrachten Initiativen entstanden Monumente, die letztlich der Legitimierung des Empereur zugute kommen sollten, indem sie nahe Angehörige des Herrscherhauses erinnerten und personale Kontinui-

5 Vgl. Brief Clésingers an Napoleon III. vom September 1855, AN F 814 Dossier: Renvoi des Tuileries au Louvre. Von einer Probeaufstellung berichtete ausschließlich aus ästhetisch-künstlerischer Perspektive Le Siècle, 29. Januar 1856, S. 3.

6 Vgl. Arrêté (vermutlich vom Januar 1863), AN F 814 Dossier: Réunion des Tuileries au Louvre. Vgl. auch BRESC-BAUTIER, PINGEOT, Sculptures Bd. 1, S. 113 und Bd. 2, S. $93 \mathrm{f}$.

7 Kurzfristig kam nach 1860 die Errichtung eines Napoleon III.-Denkmals am Eingang der Place du Carrousel nahe des Louvre zustande, überlebte aber nicht den Regimewechsel zur Republik. Vgl. ohne Belege Hargrove, Les statues de Paris, S. 252. Zum Projekt des François I ${ }^{\text {er }}$-Denkmals im Louvre-Innenhof Jean-Pierre BABELON, La Cour Carrée du Louvre. Les tentatives des siècles pour maitriser un espace urbain mal défini, in: Bulletin Monumental 142 (1984) S. 41-81, hier S. 67-72

8 Vgl. die wenigen Hinweise nach L. GREDER, Le $»$ Nu Héroïque« à Montmartre. La statue de Napoléon au Square Vintimille, in: Bulletin de la Société d'Histoire et d'Archéologie des $\mathrm{LX}^{\mathrm{e}}$ et XVII ${ }^{\mathrm{e}}$ arrondissements, Le Vieux Montmartre $\mathrm{IV}^{\mathrm{t}}$ série, Bd. 3 (années 19011905), Paris 1906, S. 234f.; Le Temps, 29. August 1869, S. 2.

9 Vgl. [An.,] Projet à son Excellence monsieur le comte de Persigny, ministre de l'Intérieur, de l'agriculture et du commerce (signé: les membres du comité de souscription nationale pour la statue équestre de Sa Majesté l'Empereur Napoléon III), o. O. o. J. [handschriftlich, up]. Vgl. auch [HUMBERT,] Proposition faite par la presse française pour l'érection d'un Monument élevé à la gloire de Napoléon III., Mirecourt 1883 [par H.].

${ }^{10}$ Vgl. [An.,] Projet à son Excellence monsieur le comte de Persigny, S. 6. [H. i. O.]. 
täten zwischen ihm und Napoleon I. veranschaulichten. So kam im August $1863^{11}$ auf dem nach ihm benannten Boulevard im 11. Arrondissement ein Denkmal für den Stiefsohn Napoleons I., Eugène de Beauharnais, zustande, der als Vizekönig von Italien zu den familiären Verwaltungsstützen des Kaiserreichs nach 1805 gezählt und dort den Zusammenbruch des Empire 1814 erlebt hatte. Im bereits 1854 publizierten Subskriptionsaufruf, den der Vorsitzende des überwiegend aus Militärs bestehenden Komitees unterzeichnet hatte, wurde Eugène als guter Regent an der Spitze Italiens, als Reorganisator der Armee, Förderer der Infrastruktur, des Rechts- und Bildungswesens, und schließlich als effizienter Vertreter des »ordre« und des altruistischen »désintéressement« apostrophiert ${ }^{12}$. Zugleich wurde die Phase der Kapitulation 1814 als passabler Versuch deklariert, das Königreich Italien zu erhalten und von Eugènes Flucht nach Bayem erst nach der Feststellung erbitterter Gegenwehr berichtet ${ }^{13}$. Das erst knapp zehn Jahre nach den ersten Spendenaufrufen aufgestellte Monument stand demnach zunächst einmal für die Herrschaft der napoleonischen Familie und die territoriale Ausdehnung der imperialen Nation vor der Katastrophe von 1814/15, die Napoleon III. außenpolitisch zu kompensieren suchte. Zugleich lag mit dem Beauharnais-Denkmal einer der wenigen Fälle vor, in denen versucht wurde, das Monopol republikanischer Symbolorte, das von jeher mit Bastilleplatz und Julisäule samt dem Faubourg Saint-Antoine und dem Père Lachaise-Friedhof im Osten der Kapitale gelegen war, durch Zeichensetzungen des Empire demonstrativ zu brechen.

1867 folgte auf Betreiben der Stadt Paris ein überlebensgroßes Marmordenkmal für die 1814 verstorbene Gattin Napoleons I. und 1804 mit ihm zur Kaiserin gekrönte Joséphine de Beauharnais. An ihrem Todestag am 30. Mai wurde es auf dem gleichnamigen Boulevard de l'Impératrice Joséphine (heute Avenue Marceau), einer der acht sternförmig auf die Place de l'Étoile einmündenden großen Straßen an der westlichen Grenze des 16. Arrondissements, enthüllt. Eine aus diesem Anlaß publizierte Schrift thematisierte die Kaiserin nicht nur als emotional-affektiven Bezugspunkt der Nation, als »l'ange consolateur des malheureux«, sondern verklärte sie auch zur quasi-religiösen Kultfigur, als »la providence des pauvres«, »saint[e]« und »relique de tous les Français $\aleph^{14}$. Die Stilisierung zur Impératrice »du peuple« zielte letztlich wieder auf die Figur Napoleons, an dessen Seite Joséphine als »la digne compagne de ce grand martyre ${ }^{15}$ zur sekundären Begleitfigur schrumpfte. So sollte zwar Affek-

11 Vgl. zur Datierung HARGROVE, Les statues de Paris. La représentation, S. 242.

12 Vgl. [An.,] Souscription Nationale. Monument à élever à la mémoire du Prince Eugène Beauharnais, Paris 1854, S. 1-2.

13 Vgl. ibid.

14 Vgl.[An.,] La statue de l'Impératrice Joséphine, suivie de sa biographie historique, o.O [Paris] 1867, S. 2 und 4.

15 Vgl. ibid. S. 4. 
tion für Joséphine geweckt, hauptsächlich aber das gesamte Herrscherhaus und beide Empereurs populär gemacht werden.

Das öffentliche Echo auf die Denkmaleinweihung blieb bescheiden. Im Artiste allerdings diente der Kommentar zum Denkmal dem kontrastiven Vergleich der außenpolitischen Situation Frankreichs 1814 und 1867 und bot Gelegenheit, die kriegerische Profilierung der Nation hervorzuheben: Im Mai 1814 hatte sich die Kaiserin mit Zar Alexander I. im besetzten Frankreich aufgehalten; ein halbes Jahrhundert später empfing Napoleon III. den Neffen des Zaren, Alexander II., als Freund und Gast ${ }^{16}$. Der Vergleich implizierte, daß Napoleon III. inzwischen im Krimkrieg das zaristische Rußland hatte demütigen können ${ }^{17}$. Damit schien nicht nur die schmachvoll empfundene Niederlage Frankreichs von 1814/15 gerächt, unter deren Folgen es, beaufsichtigt von der russischen Garantiemacht, gelitten hatte. Napoleon hatte Frankreich damit zugleich eine gestärkte Stellung auf dem Kontinent sichern können. Daß inzwischen bis Mitte der 1860er Jahre diverse außenpolitische Rückschläge und innenpolitische Krisen die Bilanz des zweiten Empereur verschlechtert und längst innere Opposition provoziert hatten ${ }^{18}$, wurde drei Jahre vor dem Sturz der Militärmonarchie übergangen.

Es war die republikanische Regierung nach 1871, die die Kaiserinnenstatue in das Denkmaldepot von Auteuil verbannte, bevor nach der Jahrhundertwende der Conseil Municipal ihre Wiedererrichtung betrieb, die allerdings auf der Avenue Montaigne, entkoppelt vom napoleonischen Symbolzentrum und nicht mehr auf einer der großen Sternstraßen stattfinden sollte. Der Vorschlag stieß zumindest nicht auf Widerspruch und zielte auch in der Tat den Betreibern der Neuaufstellung gemäß nicht auf die "politique«, sondern auf die "personnalité de l'impératrice Joséphine«, war mithin eine Frage der »conservation d'une œuvre artistique ${ }^{19}$. Historisierung bildete damit die fundamentale Voraussetzung für die erneute Aufstellung des Dynastinnendenkmals, während umgekehrt in der inzwischen gefestigten späten Dritten Republik das Monument wegen seiner Reminiszenz an das Zweite Empire nicht mehr für anstößig gehalten werden mußte und die neuerliche Assoziation der einst populären Figur nun willkommen war $^{20}$.

${ }^{16}$ Vgl. L'Artiste, Bd. 71, 1. Juli 1867 (Chronique des Beaux-Arts).

17 Vgl. hier nur Alain PLessis, De la fête impériale au mur des fédérés 1852-1871, Paris 1979 (Nouvelle Histoire de la France Contemporaine, 9), S. 187-190.

18 Vgl. Sylvie APRIE, La II ${ }^{e}$ République et le Second Empire, 1848-1870 du Prince Président à Napoléon III, Paris 2000 (Histoire politique de la France), S. 297-306, und v.a. Roger PRICE, The French Second Empire. An Anatomy of Political Power, Cambridge 2001, S. 255-395.

19 Procès-verbal du 13 juillet 1901: Renvoi à l'administration, in: CMPV, Année 1901, $2^{\circ}$ sem., S. 492.

20 Für eine tatsächliche Wiedererrichtung nach 1901 fehlen allerdings entsprechende Nachweise. 


\subsection{Reaktivierung einer autoritären Legende: Der Napoleon-Mythos zwischen offiziösem Bild und populärem Kult}

$\mathrm{Zu}$ den markantesten Zeichensetzungen während des Zweiten Empire geriet weniger eine Denkmalerrichtung oder offiziöse Einweihung als vielmehr eine symbolträchtige monumentale Modifikation. $\mathrm{Zu}$ ihr entschloß sich Napoleon III. im November 1863, als er die Napoleon-Statue auf der Vendômesäule austauschen und an die Stelle des populären »Petit Caporal« in Gehrock, Dreispitz und mit dem charakteristisch angewinkelten Arm eine Version setzen ließ, die Napoleon ähnlich wie die erste, 1810 plazierte Figur wieder im römischen Imperatorenkostüm zeigte ${ }^{21}$.

Zuvor waren in den Jahren nach dem Austausch der ersten Napoleon-Statue 1814 durch die Bourbonen gegen deren nun die Vendômesäule krönende weiBe Fahne längst dezidiert »bonapartistische« Stimmen laut geworden, wonach nur das ursprüngliche Napoleon-Standbild die ruhmvolle Vergangenheit Frankreichs adäquat erinnem könne ${ }^{22}$. Im Gefolge der Julirevolution, mit der zunächst die Trikolore an die Stelle des weißen Lilienbanners auf der Säulenspitze rückte, und unter dem Eindruck entsprechender Forderungen war schließlich Louis-Philippe zur Revitalisierung der napoleonischen Legende bereit, die die orleanistische Herrschaft aufwerten und legitimieren sollte. Mit einem exzessiv pompösen Aufwand an ephemerer Denkmaldekoration einschließlich einer bizarren, ausschließlich aus Königen und Feldherren Frankreichs bestehenden Figurengalerie auf den Esplanaden vor dem Invalidendom inszenierte Louis-Philippe zu diesem Zweck die Rückholung von Napoleons Leichnam von Sankt Helena im Dezember $1840^{23}$ und seine Beisetzung im Invalidendom. Er ließ auch am 28. Juli 1833 das neue Standbild wiedererrich-

21 Vgl. zu Genese und memorialer Funktion des Denkmals SELLIN, Napoleon, passim; MATSUDA, The memory, S. 21-23; BOIME, Hollow Icons, S. 8-9; Jörg TRÄGER, Über die Säule der Großen Armee auf der Place Vendôme in Paris, in: DERS., Friedrich PIEL ( $\mathbf{H g}$.), FS Wolfgang Braunfels, Tübingen 1977, S. 405-418; Achille MURAT, La colonne Vendôme, Paris 1970.

22 Vgl. die vielzitierte Ode an die Vendômesäule von Victor HUGO, À la Colonne de la Place Vendôme, Ode, Paris ${ }^{2} 1827$, S. 10, mit der Hugo zugleich erstmals öffentlich als Kritiker der Monarchie auf sich aufmerksam machte; vgl. Jules GARSON, L'évolution napoléonienne de Victor Hugo sous la Restauration, Paris 1900, S. 14-16. Vgl. auch Auguste Hus, La Colonne de la Place Vendôme bourbonisée, Paris 1822 [1 ${ }^{\text {er }}$ septembre]. Zur deutschen Rezeption vgl. Ludwig BOERNE, Die Vendôme-Säule 1822/24, in: Sämtliche Schriften, Bd. 2, Düsseldorf 1964, S. 102.

23 Vgl. Uwe FLECKNER, Le retour des cendres de Napoléon. Vergängliche Denkmäler zur Domestizierung einer Legende, in: DIERS (Hg.), Mo(nu)mente, S. 61-76; Jean TULARD, Le retour des cendres, in: NORA, (Hg.), Les lieux de mémoire II, Bd. 3, S. 81-110. 
$\operatorname{ten}^{24}$, das die Versöhnung der militärischen Ruhmes- mit der nachrevolutionärkonstitutionellen Freiheitsgeschichte Frankreichs in einem konsensträchtigen "monument national $\aleph^{25}$ illustrieren sollte ${ }^{26}$, und nun Napoleon in Militärmantel und Dreispitz zum Feldherrn der Grande Armée von 1805 historisierte. In diesem Sinne feierte man die neue Statue auch als Wiedergutmachung für den den Alliierten angelasteten Denkmalsturz von $1814^{27}$.

$\mathrm{Da} ß$ der Bürgerkönig die Legitimierungspotentiale des Repräsentanten der "grande nation « für sich zu nutzen wußte, bescheinigte ihm nicht zuletzt die österreichische Kaisertochter und Witwe des Empereur, Marie-Louise, die im denkmalpolitischen Akt das Initialmoment für einen personalen Loyalitätsschub zugunsten Louis-Philippes und die innere Einung der Nation zu erkennen glaubte ${ }^{28}$. Die Kultfigur, die die Julimonarchie feiern ließ, thematisierte mithin die bellizistische und monarchische Nation, deren große Heerführer ihr Territorium arrondierten, während die Rolle des »peuple« darin bestand, den soldatischen Gefolgschaftseid zu leisten.

Waren die revolutionären Barrikadenkämpfe 1848 und der Staatsstreich vom Winter 1851 spurlos an der Vendômesäule vorbeigegangen, so verfiel Napoleon III. nach inzwischen etwa zehnjähriger Herrschaft auf den Plan, das renommierte Napoleonbild auszulagern und durch eine Figur zu ersetzen, die in Anlehnung an die erste Statue im römischen Kostüm gearbeitet worden war ${ }^{29}$. Während der Julimonarchie hatte die Napoleon-Statue nur wieder auf die

24 Vgl. [An.,] Les statues de Napoléon I I , Paris 1863 [up]; [An.,] Dithyrambe. Réinstallation de la statue de Napoléon sur la Colonne de la Place Vendôme, le 18 juillet 1833, Paris 1833.

25 [An.,] La Colonne. L'ancienne statue de Napoléon et la nouvelle, o. O. o. J. [28. Juni 1833], S. 4.

${ }^{26} \mathrm{Vgl}$. ibid. S. 3. Zu Wettbewerb, Neuaufstellung und politischem Symboleffekt vgl. auch SELLIN, Napoleon, S. 392-393.

${ }^{27}$ Die Entfernung der Statue war rasch zum feindlichen Akt der Alliierten uminterpretiert worden. Vgl. [An.,] Les statues de Napoléon, passim; [An.,] La Colonne Vendôme, Paris o. J. [1863], S. 7. Entsprechend hämisch war auch die langwierige Operation der Abtragung der Statue kommentiert worden, vgl. Hippolyte DURAND, Notice biographique sur Napoléon $I^{\text {er }}$. Détails sur l'érection de sa statue en Empereur romain sur la colonne de la Grande Armée, Paris 1863, S. 7; F. LETELLIER, La culotte et le jupon. - Napoléon sur la colonne, o. O. o. J., up; [An.,] Anniversaire de la mort de Napoléon-le-Grand, détails interéssants sur la statue de l'empereur qui doit être placée sur la colonne de la Place Vendôme, o. O. o. J. [up]; textidentisch mit [An.,] La mort de Napoléon, détails interéssants sur la statue (...). Chant dédié aux braves compagnons de sa gloire, o. 0 . o. J. [1833]. Vgl. auch [An.,] Napoléon dans les cent jours ou Le Portrait du Héros sur la Colonne de la Place Vendôme, Paris 1831, S. 5.

28 Lettre de Marie-Louise, ex-impératrice des Français, à S.M. Louis Philippe I ${ }^{\text {er }}$, Roi des Français, concernant la statue de son illustre époux, relevée sur la colonne de la Place Vendôme, à la mémoire des Armées Françaises, 29 d'auguste 1834, o. O. o. J. [up]: „Un jour la France, reconnaissante, de votre bonté, vous donnera des preuves de son attachement, en se réunissant tous sous un même drapeau national."

29 Vgl. L'Artiste 5, 15. November 1863, S. 219. 
Säule geholt werden können, nachdem sie stilistisch an die Säulenreliefs angeglichen und der Empereur so zum historischen Repräsentanten der »gloire militaire« von 1805 relativiert worden war. Diese Symbolik sollte nun zurückgenommen, die Napoleongestalt erneut ästhetisch antikisiert und programmatisch überhöht werden ${ }^{30}$. Einweihungsfeierlichkeiten wie 1810 und 1833 blieben auf Wunsch Napoleons III. 1863 jedoch aus. Statt dessen wurde am späten Vormittag des 4. November im Beisein einer "foule considérable« die neue Statue aufgestellt, deren Platz am Vortag geräumt worden war $^{31}$. Der Rekurs auf die imperiale Tradition des ersten Kaiserreiches, die sich in der Form der Imperatorenfigur widerspiegelte, mußte offensiv und provokant wirken in einer Phase parlamentarischer Liberalisierung und wachsender Bedeutung der republikanischen Opposition, die Zulauf erhielt, gerade weil sie sich mit dem Wandel zur parlamentarischen Monarchie und folglich mit der politischen Binnenausstattung der Nation statt mit ihrem macht- und außenpolitischen Profil auseinandersetzte ${ }^{32}$.

Das abgenommene Standbild wurde noch am Nachmittag des gleichen Tages nach Courbevoie verfrachtet, um auf dem Rond-point de Courbevoie ganz in der nordwestlichen Vorstadt, an der Avenue de Neuilly auf einem kolossalen Granitsockel aufgestellt zu werden. Dort befand es sich auf der Sichtachse, an deren rückwärtigem Ende die Kaserne von Courbevoie, am vorderen Ende auf der gegenüberliegenden Seineseite der von Napoleon I. initiierte Triumphbogen am Place de l'Étoile lag, auf den hin die Figur nun ausgerichtet wurde ${ }^{33}$. Im zeitgenössischen Bewußtsein repräsentierte Courbevoie darüber hinaus den Ort, an dem ehedem die von St. Helena auf dem Schiffsweg bis Cherbourg und dann Seine-aufwärts zurücktransportierten sterblichen Überreste Napoleons 1840 im Rahmen des gigantischen Rückführungsspektakels erstmals wieder auf französischem Boden angelangt waren ${ }^{34}$. Insofern wurde die Statue nur aus dem unmittelbaren Stadtzentrum entfernt, um mit einem anderen renommierten Symbolort des Ersten Empire in einen Wirkungszusammenhang zu kommen.

Dies zeugte vom geschickten strategischen Arrangement Napoleons III., der den Austausch der Statuen dazu nutzte, nationale Bildsymbole zu verdoppeln und die bildliche stradition ${ }^{35}$ umzudeuten. In Courbevoie blieb die populäre nationale Kultfigur des ersten Empereur erhalten, um die sich von jeher die

Vgl. TRUESDELL, Spectacular Politics, S. 157f.; SELLIN, Napoleon, S. 392. Zur wachsenden Rolle der politischen Opposition vgl. Alain PLESSIS, De la fête impériale au mur des fédérés 1852-1871, Paris 1979 (Nouvelle Histoire de la France contemporaine, 9), S. 204210.

33

34

35

Vgl. SELLIN, Napoleon, S. 392.

Vgl. Le Constitutionnel, ibid.; Le Temps, 5. November 1863, S. 2. Zur Räumung am 3. November $1863 \mathrm{vgl}$ [An.] La Colonne Vendôme S 3

Vgl. [An.,] Les statues de Napoléon $I^{\text {tr }}$ [up]; Le Constitutionnel, 5. November 1863, S. 2.

[An.,] Les statues de Napoléon I ${ }^{\text {er }}$.

[An.,] La Colonne Vendôme, S. 2. 
Napoleon-Legende einer umfangreichen Publizistik und poetischen Literatur rankte. Zu ihr ging Napoleon III. aber auf Distanz, ohne sie als museales Ausstattungsstück in den abgeschirmten, womöglich nicht-öffentlichen Innenraum abzudrängen. Auch zeitgenössische Kommentatoren wußten sein Gespür dafür zu schätzen »que la statue actuelle [i.e. die nach Courbevoie ausgelagerte Statue, H.R.], consacrée par trente années et représentant le costume militaire si connu du monde entier, devrait rester sous les yeux du peuple et de l'armée (...) $\varkappa^{36}$. Unterdessen evozierte die neue, jetzt betont imperiale Figur im unmittelbaren Stadtkern auf der Vendômesäule machtpolitische Aspirationen des Herrschers, der es aber vermied, das Bildprogramm im Rahmen öffentlicher Feiem zu versprachlichen und somit zu vereindeutigen, um es statt dessen subtil unanstößig wirken zu lassen.

Dem eher knappen Pressevotum zum Statuenaustausch zufolge verfing diese Strategie Napoleons III. nur bedingt. Der populäre Petit Journal und die katholische Union nahmen von den Vorgängen in der Tat kaum Notiz; eine »opération délicate « vermochte die Union lediglich im technisch aufwendigen Verfahren, nicht aber hinsichtlich seiner politischen Implikationen zu erkennen ${ }^{37}$. Nur der Constitutionnel begrüßte die Reminiszenz an die "épopée impériale ${ }^{38}$. Im liberalen Temps hingegen suchte sich A. Nefftzer einer kritischen Analyse der Ereignisse zu entziehen, indem er die Frage des Statuenaustauschs gezielt vordergründig als ästhetische verharmloste ${ }^{39}$ und die neue, im römischen Stil gehaltene Napoleon-Figur auf der nur allzu deutlich vom Beginn des Jahrhunderts geprägten Vendômesäule als stilistische »cacophonie« mißbillig$\mathrm{te}^{40}$. Auch Edmond Texier hob im republikanischen Siècle sein Urteil vordergründig auf die Ebene des ästhetischen Arguments, um eigentlich politischkonzeptionelle Kritik zu üben ${ }^{41}$. Kritisiert wurde dann, daß die "statue essentiellement française « mit dem Austausch von 1863 der »statue romaine«, daß der Napoleon »du peuple« dem Napoleon als »souverain« weichen mußte. Nur die jetzt entfernte Korporal-Figur schien aber der »imagination« des Volkes vertraut, während die apotheotisch verklärte Imperatorengestalt unverständlich bleiben würde ${ }^{42}$. Mit den Kultfigurformen kontrastierte Texier faktisch zwei Nationskonzepte: Er favorisierte die französische Nation, die sich als "peuple« den Petit Caporal seit der Julimonarchie längst als glorreichen Helden im Zuge der Legendenbildung zu eigen gemacht hatte. Eines offiziös dekretierten, hoheitlich-zeremoniellen Souveräns hingegen, wie ihn Napoleon III. nun mit der

\footnotetext{
${ }^{36}$ [An.,] Les statues de Napoléon ${ }^{\text {Ier; }}$, vgl. ähnlich [An.,] La Colonne Vendôme, S. 8.

37 Vgl. L'Union, 5. und 6. November 1863, S. 1; Le Petit Journal, 6. November 1863, S. 1.

38 Le Constitutionnel, 5. November 1863, S. 2.

${ }^{39} \mathrm{Vgl}$. Le Temps, 1. November 1863, S. 1 [NEFFTZER]

$40 \mathrm{Vgl}$. Le Temps, 2. November 1863, S. 1 [NEFFTZER]; ibid. 5. November 1863, S. 2.

41 Vgl. Le Siècle, 1. November 1863, S. 2 [TEXIER].

${ }^{42} \mathrm{Vgl}$. auch Le Siècle vom 4 . November $1863, \mathrm{~S}$. 1
} 
Imperatorenfigur zu inszenieren unternahm, bedurfte es Texier zufolge nicht. Die verdeckte Kritik zeugte zugleich vom längst geschwundenen Konsenseffekt, den die Napoleon-Figur nur noch zu entwickeln vermochte, seit das Ende der Zweiten Republik und die Gründung des Zweiten Empire per Staatsstreich zu einer kritischen Revision der romantischen Napoleonlegende der 1840er Jahre veranlaßt hatten ${ }^{43}$. Der visuell auf der Spitze der Colonne Vendôme und diskursiv auf der Ebene der politischen Historiographie seiner Legende vom revolutionären Retter der "patrie« entkleidete Napoleon taugte zumindest nicht mehr als Kultfigur für eine Nationsidee, zu der nicht nur die glorreiche Selbstbehauptung nach außen, sondern auch die parlamentarische Festigung im inneren zählten.

Napoleon III. stellte sich demgegenüber mit der Imperatorfigur an die Spitze der bonapartistischen Gegenlegende, die der liberalen Diskreditierung Napoleons als dem despotischen Verhinderer innenpolitischer Freiheit entgegentrat: "Tous les jours depuis quinze ans une poignée d'écrivains se cramponne à la statue de l'Empereur, cherche à la déraciner de son socle pour le traîner dans la boue, et assouvir sur elle son dépit, sa haine, sa colère « ${ }^{44}$. Der Statuenaustausch nahm sich vor diesem Szenario als Kompensation eines rhetorischsemantischen Denkmalsturzes durch die Napoleonkritiker und als Versuch der Rehabilitierung des symbolischen Kultfigurstatus und der Aneignung der legendären Deutungstradition durch den Bonapartismus aus: »Ce culte inouï pour une mémoire (...), c'était surtout le Bonapartisme, c'est-à-dire la plus haute expression de la gloire militaire, la religion de l'honneur nationak ${ }^{45}$. Die neu errichtete Statue war die Monument gewordene Absage an die verbalen Demontageversuche liberal-republikanischer Kritiker: „Non, vous n'avez point encore (...) ôté le goût de la gloire (...). Non, malgré tous vos efforts, la statue n'est pas ébranlée. Non, malgré tous vos coups, la légende n'est pas démolie $\ll^{46}$. Mit dem Statuentransfer sollte sich dieses herrschernahe Votum durchsetzen. Zumindest in gedämpftem Ton publizierte Kritik und eine sorgsam-verhaltene Verfahrensweise Napoleons III. selbst, der wohlweislich auf einen ostentativen Festakt zur Denkmalenthüllung verzichtete, ließen das Deutungsmonopol über die bonapartistisch definierte Nation unterdessen bereits unterminiert erscheinen. Das Ende eines orthodoxen Napoleon-Kultes, wie es sich seit dem Ende der Zweiten Republik abzuzeichnen begonnen hatte, und der Legitimationsschwund, den die Fraktionierung der Gedächtnisorte zwischen der Place Vendôme zum einen und Courbevoie zum anderen unweigerlich mit

43 Zum Wandel der Napoleonlegende vgl. Jacques GODECHOT, Napoléon: pour ou contre?, in: DERS., L'Europe et l'Amérique à l'époque napoléonienne (1800-1815), Paris 1967, S. 263-292.

44 [An.,] La Légende napoléonienne et ses renégats, Paris 1869, S. 8.

45 Ibid. S. 66.

46 Ibid. S. 101. 
sich bringen mußte, nahm mit der Verdoppelung der Napoleon-Statuen monumental-definitiven Charakter an.

\subsection{Raum und Grenzen des republikanisch-oppositionellen Gegenkults}

Während des Zweiten Empire dominierte eine staatliche Denkmalpolitik, die lediglich die Idee einer militärisch glorreichen und sich aus dem Erbe des Ersten Empire speisenden Nationsordnung zuzulassen versuchte. Allerdings geriet dieses Deutungsmonpol in der Endphase der napoleonischen Regentschaft zunehmend in Bedrängnis angesichts oppositioneller Anläufe zur Begründung eigener Symbolorte und Denkmäler. Entsprechende Unterwanderungsversuche mußten dabei auf alternative Orte ausweichen, die der Reglementierung weniger zugänglich waren. Diese Funktion erfüllten in bezeichnender Übereinstimmung mit den Berliner Ereignissen um das Märzgefallenendenkmal 1848 und 1898/89 im Friedrichshain ${ }^{47}$ die großen Stadtfriedhöfe, weil ungeachtet aller kultischen Restriktionen durch die jeweiligen autoritären Regime hier ganz offenkundig flexible Anknüpfungsmöglichkeiten an das christliche Totengedenken bestanden. Das zunächst einmal christlich bestimmte Friedhofsareal erschien zunächst latent, dann provokant-offen in einen politischoppositionellen lieu de mémoire transformierbar.

Die spezifische Interferenz von Totengedenken und politischer Manifestation bot im Paris des Zweiten Empire gleich mehrere pragmatische Vorteile: zum einen konnten so bereits bestehende Kulttraditionen legitimatorisch genutzt werden, zum zweiten einer staatlichen Ordnungsmacht, die den ultramontanen Katholizismus politisch hätschelte, der rigide Zugriff auf religiös konnotiertes Terrain aus Prestigegründen erschwert werden. Drittens bot sich so auch die Chance zu einer konstruktiven statt zur nur apathischen oder destruktiven politischen Gegenwehr der republikanischen Opposition gegen das unerwünschte Empire, die sonst gelegentlich durch passive Abstinenz anläßlich von Nationalfeiertagen oder im Zuge öffentlicher Demonstrationen zum Ausdruck gekommen war ${ }^{48}$. In der Tat hatte sich in Paris seit den 1860er Jahren mit der schleichenden Liberalisierung des Systems und den daher nachlassenden Einschränkungen der Versammlungsfreiheit das Phänomen von politischen Beerdigungen bemerkbar gemacht, die man zu republikanischen Kundgebungen umfunktionierte ${ }^{49}$. Zum kultischen Knotenpunkt avancierte der

${ }^{47}$ Vgl. zu den beiden (erfolglosen) Denkmalinitiativen Teil 1, Kapitel I.2 und Teil 2 Kapitel I.2.

48

I. TRUESDELL, Spectacular politics, S. 173-181

49 Vgl. Thomas A. KsElmaN, Death and the afterlife in modern France, Princeton 1993, S. 257-290 und Philip NORD, The Republican moment. Struggles for democracy in nineteenth century France, Cambridge, Mass., London 1995, S. 197-200. 
2. November, an dem anläßlich des traditional-katholischen Festtags Allerseelen zahlreiches Publikum die Gräber von Angehörigen aufsuchte, während sich zur gleichen Zeit Regimegegner auf dem Cimetière Montmartre versammelten. Auch $1868 \mathrm{kam}$ man an diesem Tag unter anderem am Grab des umtriebigen Republikaners Godefroy Cavaignac zusammen und feierte ihn in mehreren kurzen Ansprachen als "patriote $"$ " ${ }^{50}$. Von hier aus zog die Menge weiter zur Ruhestätte Alphonse Baudins, der als republikanisches Mitglied der Assemblée während der Pariser Barrikadenkämpfe gegen das per Staatsstreich oktroyierte Empire Napoleons III. 1851 getötet worden war ${ }^{51}$. An seinem mit einem Stein und der Aufschrift Baudin, mort représentant du peuple, le 3 décembre 1851« markierten Grab folgten nun erneut Ansprachen und Kranzniederlegungen $^{52}$. Darüber hinaus lancierte die oppositionelle Presse, angeführt von den Chefredakteuren des republikanischen Réveil, Louis Charles Delescluze, und des Avenir national, Jean-Alphonse Peyrat, am 4. November 1868 einen öffentlichen Subskriptionsaufruf. Hier wurde zu Spenden zugunsten eines Denkmals aufgerufen, mit dem Alphonse Baudin als wreprésentant héroïque (...) [de] la démocratie« auf dem Cimetière Montmartre verewigt werden sollte ${ }^{53}$. In einem begleitenden Artikel von Peyrat wurde als diskursiver Hintergrund dieser Initiative rasch eine intensive Debatte um den Staatsstreich vom 2. Dezember 1851 deutlich, die im Kern um die Frage des Erinnerns dieser Geschehnisse kreiste. Peyrat nämlich warf den Verteidigern des Staatsstreichs vor, dessen gewalttätige Folgen, angefangen mit der Niederschlagung der Aufstände vor allem in den östlichen Vierteln von Paris bis zum Abend des 4. Dezember 1851, dem Vergessen anheim geben zu wollen und pochte demgegenüber auf das Recht und das Beharrungsvermögen authentischer Erinnerung: "C'est en vain que les défenseurs du coup d'État ont compté sur le temps pour effacer le souvenir de la journée du 4 décembre; ce souvenir est indélébile; il vit pour eux comme pour nous. Le Temps ne l'effacera pas $\aleph^{54}$. Auch Nefftzer warf im Temps dem Staat vor, gleichsam die Verjährung der öffentlichen Memoria erzwingen zu wollen und unterstrich um so nachdrückli-

so Vgl. L'Avenir National, 4. November 1868, S. 1. Vgl. auch TRUESDELL, Spectacular Politics, S. 182f.

51 Vgl. AGULHON, 1848 ou l'apprentissage de la République, S. 169-172.

52 Vgl. L'Avenir National, 4. November 1868, S. 1. Der Avenir bezifferte die Menge an politisch motivierten Friedhofsbesuchern während des Tages auf 15.000 Menschen. Vgl. auch Le Temps, 7. November 1868, S. I [NEFFTZER].

53 Vgl. L'Avenir National, 4. November 1868, S. 1. Vgl. zur "Affaire Baudin« auch knapp Klaus DEINET, Die mimetische Revolution oder die französische Linke und die ReInszenierung der Französischen Revolution im 19. Jahrhundert (1830-1871), Stuttgart 2001 (Beihefte der Francia, 50), S. 356 und 359; zu Delescluzes' politischer Rolle vgl. ibid. S. 272-275 und S. 346-360.

54 L'Avenir National, ibid. [A. PEYRAT]. 
cher, daß die Ereignisse um den 2. Dezember nicht einfach aus der französischen Geschichte herausdekretiert werden konnten ${ }^{55}$.

In den kommenden Tagen griffen die republikanischen Blätter die Legende von Baudins Widerstand in der Version auf, die Eugène Tenot, seinerseits Redakteur des republikanischen Siècle, im Rahmen seiner Abhandlung über den Staatsstreich vorgelegt hatte. Tenot stilisierte die Erschießung Baudins und den Kampf seiner Gefährten einerseits zum Gründungsmythos des Parti républicain, andererseits zur gesamtnationalen Bewährung der »démocratie française«, indem er die Aktivisten auf den Barrikaden in der rue du Faubourg-SaintAntoine als sozial inhomogene, nur durch das republikanische Credo geeinte Gruppe beschrieb, die sich überwiegend aus Arbeitern, kleinen Handwerkern und "patrons" zusammensetzte, ebenso aber von hochrangigen Amtsträgern wie dem ehemaligen Außenminister Jules Bastide unterstützt wurde und schließlich auch von Schriftstellern, Journalisten, Offizieren, Medizinern, und Anwälten aus den unterschiedlichsten politischen Lagern ${ }^{56}$. In Tenots Darstellung übernahmen nicht nur die Aufständischen eine Vorreiterrolle gegenüber der lethargischen "masse (...) inactive $"$ " auch zum Fanal für die Ausweitung der Kämpfe und eine breite Solidarisierung der Bevölkerung des Faubourg mit den Aufständischen ${ }^{58}$. Demzufolge barg der oppositionelle Barrikadenkampf ungeachtet seiner raschen Niederschlagung durch die Armee ein zukunftsweisendes Potential für jedwede republikanische Empörung gegen einen autoritären $\mathrm{Staat}^{59}$.

Kurz nach der Subskriptionseröffnung ${ }^{60}$, der sich nach und nach immer mehr Presseorgane anschlossen, wurden die Redakteure des Avenir und des Réveil richterlich vorgeladen und die Subskriptionslisten zunächst sporadisch, dann flächendeckend konfisziert. Delescluze und andere Angeklagte erhielten Haft-

55 Vgl. Le Temps, 12. November 1868, S. 1 [A. NEFFTZER].

${ }^{56}$ Vgl. Eugène TENOT, Paris en décembre. Etude historique sur le Coup d'État, Paris ${ }^{12} 1868$, S. 127-142, hier S. 137-138.

57 Vgl. ibid. S. 139.

58 Vgl. ibid. S. 14lf.

59 Vgl. mit zahlreichen TENOT-Zitaten und demselben Tenor auch L'Avenir National, 5. November 1868, S. 1 [MAHIAS].

60 Das eher virtuelle Subskribentenprofil für das zunächst verhinderte Denkmal zugunsten Baudins im Dezember 1868 ließ eine breite soziale Streuung erkennen. Dies gab A. Neffzer Gelegenheit, den staatlichen Vorwurf der Parteilichkeit des Unterfangens zurückzuweisen. Vgl. Le Temps, 7. und 10. November 1868, S. I [A. NEFFTZER]; L'Union, 12. November 1868, S. 1. Am 10. November konnte der Avenir National Subskriptionseingänge in Höhe von 20 Francs sowohl von Louis Blanc als auch von Victor Hugo verbuchen, die ihre Beiträge mit nachdrücklich zustimmenden Voten zur Denkmalerrichtung verbanden; vgl. L'Avenir National, 10. November 1868, S. 1. Unter anderem schlossen sich am 10. und 11. November Le Temps, Le journal de Paris und Le Siècle der Subskription an. Bis zum 12. November folgte die Provinzpresse. 
und Geldstrafen, ihre Journale teilweise Publikationsverbote ${ }^{61}$. Die Subskription wurde schließlich ganz gestoppt und die inzwischen gesammelten Gelder der Familie Baudins überlassen ${ }^{62}$. Der Cimetière Montmartre kam nach der Prozeßwelle am 3. Dezember 1868 unter rigide staatliche Aufsicht ${ }^{63}$, um, wie der Radikalsozialist Charles Floquet in der Revue politique mutmaßte, eine "seconde bataille de Clichy ${ }^{64}$ abzuwehren, die sich anders als 1814/15 nicht gegen den äußeren, sondern nun gegen den inneren, am Grab Baudins versammelten Feind der autoritären Nation richten würde. Die Bildung einer Gegenöffentlichkeit und eines alternativen, nicht vom Empire okkupierten Symbolortes für die Gegner des Staatsstreichs sollte auf diesem Wege unterbunden werden.

Im Anschluß an den Prozeß, mit dem der Staat die oppositionelle Presse überzogen hatte, erschienen mit dessen Einverständnis ${ }^{65}$ die Verhandlungsprotokolle ${ }^{66}$, die ein Schlaglicht auf den politischen Diskurs um die Kultfigur Baudin warfen. Die Kläger des Tribunal bezichtigten die Initiatoren der Versammlung auf dem Cimetière de Monmartre, bereits mit der Ortswahl einen Affront gegen Regierung und Religion provoziert zu haben, indem sie den schützenden Ort des Totengedenkens anläßlich des Feiertags Allerseelen zur Stimulierung eines »sentiment populaire« zugunsten Baudins mißbrauchten. Der Subskriptionsaufruf schließlich zeuge von der demagogischen und revolutionären Absicht des "parti démocratique«, öffentliche Unruhe gegen das Empire zu stiften. Die Klage gipfelte in der Diskreditierung der Denkmalstifter als "vaincus de la nation, du suffrage universel, du peuple souverain«, dessen plebiszitäres Votum für Napoleon III. sie vergeblich attackierten ${ }^{67}$.

Demgegenüber warf Léon Gambetta in seiner Rolle als Verteidiger von Delescluze der Anklage vor, lediglich die von seinem Mandanten betriebene symbolische Erinnerung der Republik als alternatives Ordnungskonzept der Nation hintertreiben zu wollen. Er übernahm Delescluzes Deutung des Staatsstreichs als organisierte Verschwörung gegen die "volonté nationale«: Daß offiziell nie ein auf den Staatsstreich am 2. Dezember 1851 zielender Gründungsmythos von Napoleon III. eingefuihrt worden sei, obgleich alle vorherigen Regime Frankreichs ihre Nationalfeiertage nach dergleichen Initiationsakten gewählt hatten, wertete Gambetta als Beweis dafür, daß die Regierung um

${ }^{61}$ Vgl. L'Union, 16. November 1868, S. 1 .

62 Vgl. u. a. Le Temps, 23. November 1868 , S. 2.

${ }^{63} \mathrm{Vgl}$. Le Temps, 4. und 5. Dezember 1868, S. I [Ch. DU BOUZET], 6. Dezember 1868, S. 1 [Jules FERRY]; L'Union, 5. Dezember 1868, S. 1 [Henry DE RIANCEY]

64 Zitiert nach Le Temps, 7. Dezember 1868, S. 1 [A. GAULIER]

${ }^{65} \mathrm{Vgl}$. Le Temps, 28. November 1868, S. 1 [A. NEFFTZER].

${ }^{66} \mathrm{Vgl}$. [An.,] Affaire de la Souscription Baudin. Seul rendu complet recueilli par la sténographie et revu par les défenseurs, Paris 1868.

67 Vgl. Réquisitoire de M. l'avocat impérial Aulois, 13. November, in: [An.,] Affaire, S. 2648, 26f. und 40 . 
ihr Legalitätsdefizit ebensogut wußte wie seinerzeit Napoleon I., der aus denselben Gründen auf eine Stilisierung des 18 . Brumaire verzichtet hatte ${ }^{68}$. So wenig Gambetta damit letztlich Delescluzes Inhaftierung verhindern konnte, verhalf ihm doch dieses von der oppositionellen Öffentlichkeit vielbeachtete Plädoyer zu nachhaltigem politischem Erfolg und brachte ihm bereits wenige Wochen nach Abschluß des Verfahrens eine Kandidatur für den Parti démocratique bei den Wahlen in Marseille ein ${ }^{69}$.

In den folgenden Tagen wurde das staatlich verhinderte Denkmalprojekt zum Kristallisationspunkt erhitzter Debatten in der politischen Tagespresse, bei der es zunächst vor allem um die Legalität des Staatsstreichs und damit die Institutionalisierung des bestehenden Zweiten Empire ging. Den Vorwurf der regimetreuen Blätter gegen Baudin, als sinsurgé» gegen die legitime Ordnung aufgetreten zu $\operatorname{sein}^{70}$, wies die liberale Presse zurück, indem sie den Staatsstreich als klaren Verfassungsversto $B$ wertete ${ }^{71}$. Der republikanische Liberale Jules Ferry sah das Empire dadurch delegitimiert, daß es sich von seinen plebiszitären Ursprüngen längst entfernt und nurmehr auf dem Einsatz bloßer "force" verlegt hatte ${ }^{72}$. Kritik an einem solchermaßen deformierten System war aus diesem Grunde, anders als die konservative France unterstellte, keine Rebellion von Minderheiten gegen die Nation. Die Nation, die ihre Regienung wählte, begab sich nämlich nicht ihres Rechts auf freien Willensentscheid, der vielmehr je neu gegenüber einer nationalen Regierung geltend gemacht werden konnte $^{73}$. Daher mündete die republikanische Kritik in das vehemente Plädoyer für ein partizipatorisches Nationskonzept, für eine "politique libérale« in Gestalt einer "participation complète du pays aux affaires publiques ${ }^{74}$.

Im Brennpunkt der Debatte blieb aber auch die Denkmalidee selbst. Im Avenir postulierte Mahias eine Art Grundrecht auf Subskriptionsausschreibungen und Denkmalerrichtungen ${ }^{75}$. In der Tat schien konsensfähig, daß »chaque parti honore ses morts, non comme ils le méritent, mais comme il l'entend, et ce sont là des affaires où la liberté n'a jamais été limitée « ${ }^{76}$. Denkmalsetzungen wurden mithin klar als Strategie einer spezifischen Interpretation und Deutung

Vgl. Plaidoirie de M. Gambetta, Avocat de M. Delescluze, 14. November 1868, in: [An.,] Affaire, S. 75-86.

Vgl. L'Univers, 18. November 1868, S. 1.

Vgl. Le Temps, 11. Dezember 1868, S. 1 [Henri BRISSON]

Vgl. L'Avenir National, 9. November 1868, S. 1; ibid. 14. November 1868, S. 1; Le Temps, 12. November 1868, S. 1; ibid. 13. November 1868, S. 1 [A. NEFFTZER].

7 Vgl. Le Temps, 21. November 1868, S. 1 [Jules FERRY].

73 Vgl. Le Temps, 13. Dezember 1868, S. 1 [A. GAULIER].

74 Le Temps, 23. November 1868, S. 1-2 [A. GAULIER].

75 L'Avenir National, 8. November 1868, S. 1: »Le fait d'ouvrir une souscription pour élever un monument à un citoyen est un fait absolument légal.«

${ }^{76}$ L'Avenir National, 11. November 1868, S. 1. 
zu tradierender Ereignisse, Personen oder Werte anerkannt ${ }^{77}$. Daneben drangen die oppositionellen Organe auf die Pressefreiheit, erinnerten die Regierung an die seit März des Jahres wirksame Liberalisierung von Zeitungsgründungen und verwahrten sich gegen die Dämonisierung der Meinungsfreiheit zur publizistischen "guerre civile $\aleph^{78}$. Hier erschien es als ein Gebot der »force morale«, mit einem disparaten Totengedenken zugleich plurale Interpretationen der Geschichte wie der politischen Gegenwart Frankreichs zuzulassen, weil sonst nichts weniger als der Rückfall in eine vormoderne sintolérance« und einen "absolutisme religieux drohte $^{79}$. Damit klagte die Opposition weit mehr als ihr Recht auf freie Meinungsäußerung ein, reklamierte vielmehr unumwunden eigene Deutungshoheiten und das Recht auf Wahrung ihrer eigenen Erinnerung $^{80}$. Im Temps setzte Jules Ferry eine letzte argumentative Pointe, indem er die Eigenständigkeit eines kollektiven Gedächtnisses sogar zum zentralen Kriterium der Opposition überhaupt erhob ${ }^{81}$.

Anderen Kommentatoren zufolge betrieb die Regierung schlicht eine Politik der Verdrängung ${ }^{82}$ und wurde dringend aufgefordert, sich ihres gewaltsam behaupteten Gedächtnis- und Sinndeutungsmonopols zu begeben, indem sie die »images des vaincus (...) à côté de celles des vainqueurs« tolerierte ${ }^{83}$. Die Ereignisse um den 2. Dezember 1851 sollten nicht länger nach Maßgabe einer whistoire (...) écrite que par les vainceurs« tradiert werden, sondern waren als eine Art Geschichte der Unterlegenen neu zu schreiben ${ }^{84}$. Offiziöse Geschichtsbilder, wie sie das napoleonische Regime in seinen eigenen Denkmalsetzungen zu perpetuieren versucht hatte, wurden damit als tendenziöse Sieger-Konstrukte entlarvt und bereits vor $1871 \mathrm{mit}$ dem Topos einer spezifischen Niederlagenerfahrung konfrontiert, die hier freilich noch nicht auf einem landesweiten kollektiven Demütigungsszenario, sondern auf der Abdrängung des politischen Liberalismus und Republikanismus durch ein autoritäres Regime fußte.

${ }^{n}$ Le Temps, 7. November 1868, S. 1 [A. NEFFTZER]. Davon ging selbst die konservativen Presse aus und deutete bisweilen vorsichtig Unverständnis für die harten staatlichen Gegenmaßnahmen an. Vgl. u. a. Le Temps, 7. November 1868, S. 7; L'Union, 8. November 1868, S. 2 und 18. November, S. 1 [Henry DE RIANCEY].

78 Vgl. Le Temps, 12. November 1868, S. 1 [A. NEFFTZER].

79 Vgl. Le Temps, 14. November 1868, S. 1 [DERS.].

${ }^{80}$ Vgl. so auch bereits Ch. QUENTIN im Le Reveil vom 29. Oktober 1868.

81 Ihr zugerechnet wurden Schriftsteller, Leser, Journalisten und Abonnenten, als itous ceux qui (...) entretiennent ce grand foyer de libre pensée, de critique politique, de souvenirs du passé, d'espérance d'avenir, qui s'appelle d'un mot: l'opposition.«, Le Temps, 16. November 1868, S. 1 [Jules FERRY].

${ }^{82} \mathrm{Vgl}$. Le Temps, 22. November 1868, S. 1 [A. NEFFTZER]: »le souvenir dont il s'agit doit demeurer éternellement oublié ou proscrit.«

${ }^{83}$ Vgl. ibid.

84 Le Temps, 23. November 1868, S. 1 [A. GAULER]; L'Union, 14. November 1868, S. 1. 
Die Differenzierung zwischen dem Kollektivgedächtnis von Siegern und Besiegten und die Einsicht, daß im Perpetuieren eines Gedächtnisses zugunsten der Unterlegenen die Chance lag, zu einer regelrecht geläuterten Zielutopie der Nation zu gelangen, mit der man der Siegerlogik trotzen konnte, blieb der zukunftsträchtige Erkenntnisgewinn der liberalen Opposition im Disput um eine eigenständige Denkmalsymbolik.

\section{Berlin: Konterrevolutionäre Kontinuitätsgarantien der preußischen Dynasten}

Auch wenn ihre Vorgeschichten bis weit vor die Jahrhundertmitte zurückreichten, zeugten die beiden Monarchendenkmäler, die 1849 und 1851 in Berlin aufgestellt wurden, klar von dynastischen Deutungshoheiten mindestens über das monumentale Bild der Nation.

Zunächst wurde die Revolution von 1848 bereits ein Jahr später mit einem Monument für Friedrich Wilhelm III. im Tiergarten demonstrativ übergangen. Immerhin unterschied sich dieses Standbild von den gängigen Initiativmustern und Formsprachen preußischer Herrscherdenkmäler in der Kapitale: Zum einen trat jetzt erstmals nach der Revolution eine nicht-monarchisch dominierte, wenn auch staatsnahe Initiatorengruppe auf; zum anderen erschien im innovativen Bildprogramm das Monarchenstandbild mit dem Gestus der Verbürgerlichung ${ }^{85}$ und des Unmartialischen, unterstützt von der »eigentlichen« Kultfigur Luise als Repräsentantin patriotischen Opfermuts.

Der Antrag der »Bewohner Berlins« wies zunächst alle Kennzeichen devoter Loyalitätsbezeugung auf, indem er darauf zielte sin dankbarer Erinnerung an die unzähligen Beweise königlicher Huld und Gunst, die ihnen von des Hochseligen Königs Majestät zu Theil geworden sind (...) dem in Gott ruhenden Könige und Herrn ein Denkmal unvergänglicher und treuer Verehrung ${ }^{86}{ }^{8 u}$ errichten. Dies sollte am Ort solchen Gunsterweises im Tiergarten und wherrlichsten Volksgarten« als einem harmonischen Ort der Rekreation geschehen, »dessen sich alle Bewohner der Residenz, arm und reich, hoch und niedrig, gleich innig erfreuen ${ }^{87}$. Die Stiftung adressierte den Monarchen demnach weniger als Staatsautorität denn als paternalistischen Wohltäter. Sie visierte nicht die politische Nation, sondern die städtische Gesellschaft Berlins an und entwarf das Bild nicht des aktiv berechtigten, sondern eines passiv, aber egalitär vom monarchischen Gunsterweis profitierenden »Volks«.

$85 \mathrm{Vgl}$. WIENFORT, Monarchie, S. 13

${ }^{86}$ Schreiben des Komitees vom 20. August 1841, GStA PK I. HA Rep. 89 Nr. 20914, B1 23.

${ }^{87}$ Schreiben des Komitees an den König vom 8. August 1841, ibid. BI. 24. 
In der Festrede des Komiteevorsitzenden und Generalleutnants von Reyher blieb der Tenor der Stiftungsinitiative zunächst erhalten. Die danebentretende Würdigung des »König[s] als Mensch« mobilisierte einen umfassenden Kanon bürgerlicher Werte und Lebensstile, betraf des Monarchen "Tugendleben«, "wahre Häuslichkeit«, »Erziehung" seiner Kinder und »Ehe«, die ihn "Mensch unter Menschen « werden lie ${ }^{88}$. Die harmonistischen Formeln gingen schließlich in eine Reminiszenz an die Königin über und griffen nun Versatzstücke des Kults der Luise ${ }^{89}$ auf, unter deren Tod das Volk gelitten habe, bis die Zerschlagung Preußens 1807 »bei Leipzig« vergolten werden konnte. Damit wurde zugleich dasjenige historische Initialereignis thematisiert, auf das die Einweihung auch mit dem Datum des 18. Oktober als Jahrestag der Leipziger Völkerschlacht und »Morgenröthe des neuen Deutschland " programmatisch bezogen und das ebenso wie die Luisenverehrung konsensträchtig wirken konnte. Loyalitätsbekundungen gegenüber der gegenwärtigen nachrevolutionären Monarchie blieben ungeachtet der abschließenden Hochrufe auf das Königshaus marginal. Die Rede verfolgte mithin eine doppelte Strategie: sie propagierte die wertbezogene Anverwandlung der Monarchie durch ein Bürgertum, das sich zu Teilen knapp ein Jahr zuvor seiner politischen Reformerwartungen wegen zur Revolution hatte drängen lassen. Vor allem aber geriet sie zum Politikum, indem die unmittelbar vorausliegende Revolution aus ihrem Deutungsraster herausfiel, weil der Kontinuitätsbruch verschwiegen und auf der monarchischen Tradition beharrt wurde.

Zum konterrevolutionären Fanal par excellence wurde einige Jahre später das Großprojekt des Friedrich II.-Denkmals Unter den Linden, das nach einer lange stagnierenden Vorphase zu Beginn des 19. Jahrhunderts wiederaufgegriffen und diesmal im Mai 1851 zum Abschluß gebracht wurde. Kennzeichend für die gesamte Initiative wurde der monarchische Kontrollanspruch auf Inszenierung und programmatische Sinnschöpfung des Monuments. Freilich setzten sich aber nur die Entscheidungsvorbehalte und die ikonographischkonzeptionelle Mitsprache fort, die die preußischen Monarchen sich längst im Verlauf des langwierigen Gesamtunterfangens je neu gesichert hatten ${ }^{90}$. Militärische Inszenierung und konterrevolutionärer Impetus des Monuments jedoch verdankten sich vor allem der langwierigen Entstehungsphase, durch die das Projekt ganz unter den Einfluß der tagespolitischen Dynamik des Revolutionsjahres geriet. Die Grundsteinlegungsfeier 1840 einer- und die Einweihung 1851 andererseits lagen damit auf einer Zeitschiene jenseits und diesseits der Zäsur von 1848 und verhielten sich wie bürgerlich-monarchisches Nationalfest

Vgl. dazu weiter unten.

90 Vgl. dazu bereits die Einleitung. Vgl. generell Hans MACKOWSKY, Das Friedrichsdenkmal nach den Entwürfen Schinckels und Rauchs (1822-1836), Berlin 1894. 
vor und Triumphfeier der konservativen Nation nach 1848 zueinander $^{91}$, thematisierten also die preußische Nation mit höchst unterschiedlichen programmatischen Akzenten.

Zunächst aber hatte weit vor diesem Zeitpunkt, Ende der 1820er Jahre, eine Eingabe der kurmärkischen Stände bei Friedrich Wilhelm III. am Anfang des Projekts gestanden, die auf die Würdigung des »Begründer[s] des ruhmvollsten Zeitraums in der preußischen Geschichte« und »glorreiche[m] Ahnen des Regenten« zielte. Offenkundig beabsichtigten die Stände, ein vom Monarchen bis dahin mit wenig Verve betriebenes Projekt aufzugreifen und ihrerseits als promonarchische Nationsdeuter aufzutreten ${ }^{92}$. Der Monarch bekundete demgegenüber eigene Stifterabsichten ${ }^{93}$, die bislang lediglich von den "Ereignissen der Zeit ${ }^{94}$ torpediert worden seien. Damit deutete er an, wie die reaktionär gegängelten frühnationalen Bewegungen im Gefolge der Napoleonischen Kriege in der frühen Jahrhunderthälfte geeignet waren, die öffentliche Akzeptanz eines monarchischen Denkmals zu mindern. Jedenfalls wollte der König höchstens eine materielle »Theilnahme« der Stände und weiterer »Provinzen und Landstände unserer Monarchie« zulassen ${ }^{95}$, nicht hingegen einen Sammelaufruf an alle preußischen Provinzen richten ${ }^{96}$. Das umständliche Verfahren zeugte von der monopolistischen Denkmal- wie Stifterauffassung Friedrich Wilhelms III., der so seine dynastische »Pflicht gegen das Andenken Unseres großen Vorfahren [zu] erfüllen« gedachte, während den Ständen die untertänige »Huldigung [des] dankbaren Vaterlandes« $\mathrm{oblag}^{97}$.

Mit der Grundsteinlegung am 1. Juni 1840, dem hundertjährigen Jubiläum der Thronbesteigung Friedrichs II. ${ }^{98}$, und mit der Einweihungsfeier am 31. Mai 1851, dem Todestag Friedrich Wilhelms I., wurden auch die Festdaten so gewählt, daß sich das Friedrich II.-Denkmal von den preußischen Herrscherviten her erschließen sollte. Alternative Symbolbezüge waren vorübergehend angedacht worden: So planten die Stadtverordnetenversammlung und der Magistrat von Berlin im Mai 1840 die offiziösen Feierlichkeiten des Tages aus Pietät gegenüber dem im Sterben liegenden König Friedrich Wilhelm III. nicht als "Volksbelustigung«, sondern primär als eine Reihe von pädagogischen und

91 Vgl. auch NIPPERDEY, Nationalidee und Nationaldenkmal, S. 540.

92 Vgl. Immediatvorstellung der Deputation des Provincial-Landtages der Mark Brandenburg und des Markgrafentums Niederlausitz, GStA PK I. HA Rep. 93 B Nr. 2355, Bl. 3.

93 Antwort des Königs an die Stände vom Januar 1829, GStA PK I. HA Rep. 89 Nr. 20911, Bl. 1.

94 Vgl. Landtagsbescheid, für die Brandenburgischen Stände, GStA PK I. HA Rep. 93 B Nr. 2355, Bl. 17.

95 Vgl. Beschluß des Staatsministeriums vom 2. April 1829, ibid. Bl. $13 f$.

96 Vgl. ibid. Bl. 14.

97 Vgl. Landtagsbescheid, s.o.

98 Vgl. Erlaß vom 26. März 1840, GStA PK I. HA Rep. 151 I C Nr. 8314, Bl. 1. 
karitativen Symbolakten ${ }^{99}$. In den Berliner Schulen sollten im Rahmen von Gedenkfeiern Biographien des Königs verteilt und "Friedrich-GewerbeStipendien « an junge Handwerker vergeben werden. Auch wurde erwogen, den Friedrichshain - orientiert am monarchisch gestifteten Tiergarten - als "Erholungsplatz» anzulegen und Speisungen für Invalide, Veteranen, Arme und Waisen anzubieten. Diese städtisch organisierten Reminiszenzen an Friedrich II. als 》Gründer der Industrie und des Wohlstandes seiner Unterthanen, als Beschützer der Künste und Wissenschaften, als Held, Gelehrter und Weiser« imitierten zunächst den Gestus der patriarchalischen Fürsorge und trugen im Namen des Königs sozialer Ungleichheit in der Gesellschaft Rechnung ${ }^{100}$.

Über die von den städtischen Gremien angeregten Deutungsalternativen setzte sich Friedrich Wilhelm IV. hinweg. Statt dessen gab er nun detailreiche Anweisungen für die Grundsteinlegungsfeier, die die kleinschrittige Inszenierung einer hierarchisch strukturierten Festgesellschaft vorsahen und sogar symbolträchtig festschreiben sollten, indem das Festprogramm mit dem Grundstein in das Fundament des Monarchendenkmals eingegraben wurde ${ }^{101}$. Das Zeremoniell war nicht ausschließlich von militärischen Elementen dominiert, auch wenn Truppenformationen den Festplatz umsäumten, Generäle und Offiziere als privilegierte Teilnehmer der Feier mit den Angehörigen des Königshauses vom Prinzenpalais zum Standort des künftigen Denkmals Unter den Linden zogen und die Feier mit Kanonensalven eröffnet wurde. Auf der "Linden-Allee« beherrschten nämlich auch die zahlreichen Deputationen der Handwerkerinnungen an der dem Brandenburger Tor zugewandten Seite des Platzes mit ihren Insignien das Festbild, während bischöflicher Segen und Glockengeläut das Fest beschlossen ${ }^{102}$. Der Zug von Handwerksdeputationen und Korporationen war akribisch vorbereitet ${ }^{103}$ und ihre Aufstellung als Repräsentation der »Bürger« und zentrales Element des »Nationalfestes« sogar ausdrücklich von Friedrich Wilhelm IV. angeordnet worden. So sollte ein harmonistisches Festensemble mit einem »engverbundene[n], um das geliebte Herrscherhaus gesammelte[n] Volk« enstehen ${ }^{104}$.

Vgl. Beschluß von Stadtverordnetenversammlung und Magistrat vom 20. Mai 1840; 30. Mai nach SOMMER, Gedenkbuch, S. 47-48.

$100 \mathrm{Vgl}$. ibid.

${ }^{101} \mathrm{Vgl}$. Anordnung der Feierlichkeiten bei der Grundsteinlegung des auf Allerhöchsten Befehl zum Andenken des Regierungs-Antritts Sr. Hochseligen Majestät Königs Friedrich's II. zu errichtenden Denkmals vom 30. Mai 1840, GStA PK I. HA Rep. 93 B Nr. 2355, Bl. 21.

${ }^{102} \mathrm{Vgl}$. SOMMER, Gedenkbuch, S. 52-54 und NPKZ, 1. Juni 1851, S. 1.

${ }^{103} \mathrm{Vgl}$. VON ROCHOW, Anordnung der Feierlichkeiten bei der Grundsteinlegung des auf Allerhöchsten Befehl zum Andenken des Regierungs-Antritts Sr. Hochseligen Majestät Königs Friedrich's II. zu errichtenden Denkmals, Berlin 1840.

${ }^{104}$ SOMMER, Gedenkbuch, S. 68. Zum Autor vgl. von Olfers am 16. Juli 1851 an den Finanzminister, GStA PK I. HA Rep. 151 I C Nr. 8315, Bl. 47. 
Den Grundsteinlegungsakt selber leiteten der Gouverneur der Berliner Residenz, Staatsratspräsident, preußische General und ehemalige Oberkommandierende über die preußisch-britischen Truppen 1814, Karl von Müffling, sowie der ursprünglich an der Spitze der frühen, rasch monarchisch absorbierten ständischen Denkmalinitiative stehende Minister des Inneren und der Polizei von Rochow. Von Müfflings Rede entfaltete die Vorstellung vom dank monarchischer Reformpolitik erst eigentlich zur nationalen Gemeinschaft geeinten Volk als einem zwar nicht egalitären, wohl aber inklusiven und homogenen Gesellschaftsverband. Der König habe die "Zunahme der Bildung aller Volksclassen [und] die Veredelung unserer Sitten« betrieben, »Künste und Wissenschaften (...), Gewerbthätigkeit« und Landwirtschaft »beschützt und erweitert«. In der Person des Monarchen als Fixpunkt des preußischen Volkes liefen schließlich nicht nur Krieg und Frieden, sondern auch die Zeitdimensionen von Vergangenheit, Gegenwart und Zukunft zusammen: Sein Reformwerk galt als kriegsbewährte und immer neu nach außen zu sichernde "Segnung des Friedens « zum einen, als historische Stiftung des jetzigen »besseren Zustandes« wie einer »allmählich sich immer schöner entwickelnden Zeit« zum anderen $^{105}$.

Bis zur Einweihung des Friedrich II.-Denkmals Unter den Linden $1851^{106}$ sollte sich der programmatische Tenor der Stiftung erheblich vereinseitigen. Zunächst hatten sich den Vorgaben einer von Friedrich Wilhelm IV. eingesetzten Kommission zufolge ${ }^{107}$ Abordnungen zum Festumzug förmlich anzumelden. Festgelegt war auch die Ordnung des von Kanonenschüssen angekündigten und unter Glockengeläut durchgeführten Festzugs, deren Hierarchie nur zugunsten der Bauleute aufgebrochen wurde, von denen Meister und Gehilfen zusammen mit der Kommission und den Künstlern die Spitze des Zugs bilde-

${ }^{105}$ Vgl. Müffings Rede ibid. S. 53f. Vgl. ähnlich auch der Tenor von Alexander von Humboldts Rede vor der Akademie am 1. Juni 1840, ibid. S. 69; dazu Richard NÜRNBERGER, Rauch's Friedrich-Denkmal historisch-politisch gesehen, in: JbPK 8 (1970) S. 115-124, hier S. 116.

${ }^{106}$ Vgl. Denkmal König Friedrichs des Großen, enthüllt am 31. Mai 1851, Berlin 1851; Da ist Er! Zum Gruße Berlin's an des großen Königs Standbild am 31. Mai 1851 und Erläuterung der Bildwerke an dem Denkmal, Berlin 1851; Zur Erinnerung des Denkmals Friedrichs II., 31. Mai 1851, Berlin 1851 [Berlinische Nachrichten von Staats- und gelehrten Sachen $\mathrm{N}^{\circ}$ 125]; Lieder zur Nachfeier der Enthüllung des Friedrich-Monuments, gesungen am 6. Juni 1851; Louis QUIEN, Empfindungen bei der feierlichen Enthüllung des Denkmals Friedrichs des Grossen. Den Manen des grossen Königs dargebracht, Berlin am 31. Mai 1851; Clementine SCHRADER, Am Denkmal Friedrichs des Großen, Berlin, am 31. Mai 1851. Zur kultischen Rezeption vgl. C.G. BRANDIS, Ferdinand KOHLHEIM (Hg.), Das Denkmal Friedrichs des Großen in Berlin. Beschrieben und mit Gedichten aus älterer und neuerer Zeit versehen v. F. KOHLHEIM, Berlin 1871; Walter VON ZUR WESTEN, Zur Enthüllung des Rauchschen Friedrichsdenkmals in Berlin. Fest- und Erinnerungsblätter aus Anlaß der 75. Wiederkehr des Enthüllungstages zusammengestellt, Berlin 1926.

${ }^{107}$ Vgl. Erlaß vom 8. Mai 1851, GStA PK I. HA Rep. 151 I C Nr. 8315, Bl. 28 und Bl. 60. 
ten, bevor Generäle, Minister, Geistliche beider Konfessionen, ständische und städtische Vertreter der preußischen Provinzen, Mitglieder der Kammern, Kaufleute und schließlich "patriotisch[e] und gemeinnützig[e] Vereine«, Schützengilden und die Handwerkerinnungen folgten. Den unmittelbaren Denkmalraum sah die Vossische Zeitung zumindest vor Beginn des Festzuges ebenso regelrecht von "Truppen (...) besetzt«, wie auch das weitere Areal durch ein "vom Denkmal bis zum Schloß [reichendes] (...) breites, imposantes Truppenspalier « ${ }^{108}$ militärisch okkupiert blieb. Erst die zivilen Formationen des vom Schloß her angelangten Festzuges lockerten die militärische Präsenz in unmittelbarer Denkmalnähe auf. Als Vorgriff auf einen Ritus, den die Monarchendenkmalfeste nach 1871 perpetuieren sollten ${ }^{109}$, enthüllte man das Denkmal unter Glockengeläut, Choralklängen und Kanonensalven und richtete sich so nach religiös-kirchlichen wie militärischen Ordnungszusammenhängen gleichermaßen aus. Von einer Tribüne auf dem Opernplatz aus nahm der König nach dem Defilee der Truppen auch das der Handwerksdeputationen ${ }^{110}$, der Schützengilden und der Veteranenvereine ab, die damit nicht nur die nationale Gesellschaft als nach Korporationen hierarchisch durchgliederten Verband darstellten, sondern zugleich in das militärische Zeremoniell eingebunden waren ${ }^{111}$. Schließlich bezog sich die Festszene deutlich negativ auf die Märztage von 1848: dies nicht nur mit ihrem dezidiert staatlich-militärischen Erscheinungsbild, sondern auch im Rahmen einer offiziellen SymbolReglementierung. Denn zwar galten keine Vorgaben für die Korporationen und Innungen und waren nur die Meister wie schon 1840 dazu verpflichtet, schwarz-weiße Armbinden zu tragen, »Fahnen aus dem Jahre 1848« waren jetzt aber strikt verboten. Aus Protest gegen dieses Reglement kündigte die Studentenschaft ihre Beteiligung am Festzug auf ${ }^{12}$. Das Bekenntnis zu den Idealen der Revolution zog hier den Ausschluß aus dem Fest nach sich. Revolutionäre Gegenöffentlichkeiten konnten indessen parallel zur offiziellen Feier nicht etabliert und konkurrierende Nationsentwürfe nicht unterbreitet werden: Gerüchte um eine »Gegendemonstration der Gewerbetreibenden und Arbeiter« auf dem Friedrichshain führten zu einem präventiven Polizeieinsatz am Tag der Denkmaleinweihung, ohne daß sich erkennbar Widerstand formiert hät$\mathrm{te}^{113}$. Der reaktionäre Staat zeigte sich damit bereit, sein Deutungsmonopol selbst mit rigiden Methoden zu verteidigen.

${ }^{108} \mathrm{VZ}, 1$. Juni 1851, S. 2.

${ }^{109} \mathrm{Vgl}$. dazu Teil 2, Kapitel II.2.

${ }^{110}$ SOMMER, Gedenkbuch, S. 11 If. listete 48 »Gewerke« auf, die sich am Festzug beteiligten und dabei von den ältesten Innungen, den Metzgern, Maurern und Zimmerleuten, angeführt wurden.

111 Vgl. ibid. S. 90-92, 102-106.

112 Vgl. ibid. S. 68, 95

${ }^{113}$ Dazu kamen erstmals vier ephemere Kolossalstandbilder brandenburgisch-preußischer Regenten, die dicht hinter dem Reitermonument Friedrichs II. auf obeliskartigen hohen 
Auch im Rahmen der Einweihungsfeier 1851 wurde die hauptstädtische Denkmaltopographie symbolisch integriert, war nun aber stärker von einer dezidiert preußischen Staatssymbolik beherrscht: Die Generalsstandbilder auf dem Wilhelmplatz und die Standbilder vor der Neuen Wache waren nicht mehr mit Eichenlaub, sondern mit vergoldeten Adlern und den auch an den Tribünen angebrachten schwarz-weißen Fahnen, nur gelegentlich von Flaggen mit dem Stadtwappen kontrastiert, geschmückt ${ }^{14}$. Schließlich bezog man 1851 anders als noch bei der Feier 1840 das gesamte Areal zwischen dem Pariser Platz und dem an römischer Triumpharchitektur orientierten Stadtschlo $\beta^{115}$ mit ein, indem die Innungen und Korporationen wie die Schützen, Veteranen, »Krieger der Jahre 1813 bis 15 « und der »Treuebund" vom Akademiegebäude bis zum Pariser Platz längs der Linden-Allee aufgestellt wurden und die Militärparade nach dem Ende der Feier über die Linden wieder abmarschierte. Das neue Reiterdenkmal schloß auf diese Weise zugleich die Linden-Allee im Machtzentrum krönend $\mathrm{ab}^{116}$.

Die Einweihungsreden zum Friedrich II.-Denkmal übergingen die 1840 noch prominent behandelte Reformthematik und feierten statt dessen jenseits der Zäsur von 1848 den Triumph der konservativen Nation. So reduzierte Ministerpräsident von Manteuffel in seiner Eröffnungsansprache das Frederizianische Erbe auf den Erhalt des »altpreußische[n] Sinn[s]«, der Preußen nicht nur durch die kriegerischen Anfeindungen von außen, sondern auch die revolutionären Wirren getragen habe. Als Quintessenz solchen »Altpreußentum[s]« erwies sich folglich der »alt[e] militärisch[e] Geist«, als ihr Hort die "Armee» und als ihr monarchischer Repräsentant der »Kriegsfürst. « Über der Zuordnung von "Opferwillen« und "Treue» wurde in einer den Topoi im Rahmen der Feier der Invalidensäule drei Jahre später vergleichbaren Manier ${ }^{117}$ die Revolution als definitiv besiegte und gleichwohl "finstre Macht der Verführung" diffamiert $^{118}$. Mit einer ähnlichen Metaphorik würdigte auch Friedrich Wilhelm IV. in knappen, zunächst an das Heer und erst danach an die Vertreter der Stadt Berlin adressierten Worten das Denkmal als konterrevolutionäres

Säulen in ihren Reliefs historische Szenen seit der Gründung Berlins im 12. Jh. zeigten. Vgl. ibid. S. 115.

${ }^{114}$ Vgl. Berlinische Nachrichten, 31. Mai 1851, S. 2.

${ }^{115} \mathrm{Vgl}$. DUCHHARDT, Anspruch und Architektur, S. 46-49.

${ }^{116}$ Vgl. VZ, 1. Juni 1851, S. 1-2; [An.,] Die Friedrichsfeier, S. 6-8, 19. Ähnlich wie bei den Feierlichkeiten anläßlich der Grundsteinlegung zur Invalidensäule 1850 (vgl. dazu Teil I, Kapitel III.2.1) blieb das Absingen der Preußenhymne »Heil Dir im Siegerkranz« 1840 der Festgesellschaft des städtisch organisierten Banketts vorbehalten und erfolgte nun 1851 lediglich im elitären Kreis einer Operngesellschaft, die der König am Abend des Einweihungstages gab.

${ }^{117}$ Vgl. zur Invalidensäule Teil I, Kapitel III.2.1.

${ }^{118}$ Vgl. Manteuffels Rede im Bericht der VZ vom 1. Juni 1851, S. 2f. und u. a. auch bei [An.,] Die Friedrichsfeier, S. 12-13. 
Fanal, "für Alle ein Zeichen der Versöhnung und für Viele ein Zeichen der Umkehr ${ }^{119}$ und legte sich damit auf eine uneingeschränkte Absage an die Revolution und ihre Sinnstiftungspotentiale für die Nation und ihre Geschichte fest.

Der Trend der offiziellen Zelebranten zur reaktionären Nationsdeutung setzte sich mit einer äußerst selektiven Erinnerung der Frederizianischen Epoche fort, deren reformerische zugunsten der militärischen Tradition unterschlagen wurde. In diesem Sinne bestritt auch der Verfasser des Gedenkbuchs zur Denkmalentstehung, daß die Nation aus dem revolutionären Umbruch ${ }^{120}$ habe hervorgehen können und sah ihre Zukunftsfahigkeit von der Verwurzelung in Militär und Monarchie abhängig.

Zwar visualisierte Rauchs monumentales Bildprogramm - anders als noch beim Denkmal für den Großen Kurfürsten aus dem frühen 18. Jahrhundert auf der Langen Brücke nahe der SchloBfreiheit ${ }^{121}$ - das "Volk « nicht mehr in Gestalt gebeugter Sklaven, sondern als eindrucksvolles Ensemble ruhmreicher Militärs und "großer Geister" der Epoche. Mit den abschließenden abendlichen Illuminationen ${ }^{122}$ des Denkmals und zahlreicher Repräsentationsbauten der Stadt am Einweihungstag wurde das "Volk« aber nurmehr als euphorisierbare Masse ${ }^{123}$ in die Feier einbezogen.

Das Unbehagen über die Rigidität der nachrevolutionären offiziellen Nationsdeutung in der liberalen Presse blieb latent. Die Vossische Zeitung mied es, die revolutionfeindliche, metaphernschwangere Anrede des Königs an die Armee wiederzugeben ${ }^{124}$. Ebenso überging sie Manteuffels waltpreußisches« Sinnstiftungsangebot und versuchte Denkfiguren der vorrevolutionären Nationalbewegung über die Zäsur von 1848 hinweg zu bewahren, indem sie die Friedrichs-Feier programmatisch und zukunftsgerichtet zum "Bundesfest" umwertete und der Litanei soldatischer Tugenden die emotionalen Loyalitätsbezüge des "Vertrauens, der Liebe, der Ehrfurcht« entgegenhielt ${ }^{125}$. Im liberalen Sinne tendenziös nahm sich schließlich das bereits am Einweihungstag als »ewig[e] Grundlage« des Staates veröffentlichte Zitat Friedrichs II. aus, wo-

${ }^{119}$ SOMMER, Gedenkbuch, S. 109.

${ }^{120}$ Vgl. ibid. S. 101.

${ }^{121}$ Vgl. Ulrich KELLER, Reitermonumente absolutistischer Fürsten. Staatstheoretische Voraussetzungen und politische Funktionen, München 1971, Teil IV. Das Denkmal wurde in den 1950er Jahren in den Ehrenhof des Charlottenburger Schlosses transferiert.

${ }^{122} \mathrm{Vgl}$. die suggestiven Schilderungen bei SOMMER, Gedenkbuch, S. $114 \mathrm{f}$.

${ }^{123}$ SOMMER, ibid. S. 124, veranschlagte eine Zahl von 80.000 Teilnehmern und Zuschauern an den Berliner Feiern. Das „Friedrichsfest « wurde parallel $u$. a. in Potsdam mit der Offnung der Friedrich-Gruft in der Garnisonskirche, in Stettin und Breslau mit Feiern an den dortigen Friedrich II.-Denkmälern und in Posen mit einem Tableau vivant des Berliner Monuments begangen; vgl. ibid. S. 116-123.

${ }^{124} \mathrm{Vgl}$. VZ, 1. Juni 1851, S. 3.

${ }^{125} \mathrm{Vgl}$. ibid. S. 4. 
nach gute Regentschaft Kenntnis über den »Geist der Nation« voraussetzte und nicht Willkürherrschaft über "Sklaven« bedeute, sondern "Gesetz«Mäßigkeit und „Freiheit« zu befördern habe ${ }^{126}$. Dennoch wurde auch hier mit der monarchischen Ehrung die revolutionäre Zäsur demonstrativ übergangen und mit der traditionalen Form des Reiterdenkmals der klassische Vorrang der preußischen Monarchie als politische Vorgabe für die Nation demonstriert.

$\mathrm{Zu}$ den hoheitlich-dynastischen Berliner Denkmälern eigener Art zählte demgegenüber schließlich auch die im Juni 1858 in Oranienburg errichtete Statue für Königin Luise, deren Enthüllungszeremonie vom städtischen Initiativkontext geprägt blieb. Mit dem Oranienburger Projekt entstand durchaus nicht das erste öffentliche Denkmal für die Königin. Ihm ging vor allem längst der bereits 1809 errichtete Denkmalaltar im Tiergarten nahe der Luiseninsel voraus, den ein Berliner Komitee für das aus Ostpreußen zurückgekehrte Königspaar gestiftet hatte. Neben das Motiv zeitgenössischer Empfindsamkeit war hier bereits der Kult der großen Patriotin getreten ${ }^{127}$. Anders als dieses eher landschaftliche Denkmal befand sich nun aber das Oranienburger Standbild auf dem Luisenplatz direkt vor dem Schloß ganz im urbanen Raum. Mit dem Einweihungsdatum huldigte man zugleich »dem erhabenen Stamm der Hohenzollern überhaupt ${ }^{128}$, erinnerte der 18. Juni 1858 doch nicht nur den "Sterbetag der Königin«, sondern auch den Tag des Sieges über Schweden im brandenburgischen Fehrbellin 1675 und des Sieges von Belle Alliance (Water10o) 1815. Die zahlreich anwesenden Stadtverordneten, Magistratsmitglieder, königlichen Beamten, Geistlichen, sonstige "Bürgerschaft« sowie »Gewerke» und »Schützengilde«, Schüler und Lehrer ${ }^{129}$ prägten allerdings anders als 1851 durchaus eine überwiegend unmilitärische Feierszene.

Die ohnehin einzige Rede des Bürgermeisters Kahlbaum lud die Vita der Geehrten gleichermaßen mit städtischen, regionalen und nationalen Konnotationen auf, indem Luise nicht nur als "Wohltäterin der Stadt Oranienburg« erschien, wo sie ein Waisenhaus gegründet hatte, sondern auch als "Landesmutter « der Mark Brandenburg und Prinzessin der »Nation ${ }^{130}{ }^{30}$. Zum Fixpunkt diverser Loyalitäten konnte die Figur vor allem über das Moment der christ-

${ }^{126}$ Vgl. VZ, 31. Mai 1851, S. 3: "Müßte man nicht irre sein, um sich vorzustellen, daß Menschen zu einem ihres Gleichen gesagt hätten: wir erheben Dich über uns, weil wir gern Sklaven sein möchten (...)? Sie haben im Gegentheil gesagt: Wir bedürfen Deiner, um die Gesetze aufrecht zu erhalten, denen wir gehorchen wollen (...); übrigens fordern wir von Dir Achtung für unsre Freiheit."

${ }^{127}$ Vgl. Hermann MưLLER-BOHN, Die Denkmäler Berlins. Thre Geschichte und Bedeutung Mit einem Anhang enthaltend Gedenktafeln und Wohnstätten berühmter Männer. Ein kunstgeschichtlicher Führer, Berlin 1905, S. 40; ARNDT, Denkmaltopographie, S. 182.

${ }^{128}$ NPKZ, 22. Juni 1858, S. 1.

${ }^{129} \mathrm{Vgl}$. ibid.

${ }^{130}$ Vgl. Weih-Rede zur Enthüllung des Luisendenkmals in Oranienburg am 18. Juni 1858, gehalten vom Bürgermeister Kahlbaum, GStA PK I. HA Rep. 89 Nr. 20903, Bl, 62-65. 
lich-kultischen Überhöhung zur Retterin Preußens nach dessen Kriegsniederlage 1806/07 und durch ihre regelrechte Sakralisierung und Stilisierung zur Erlösergestalt und zum »Sendbote[n] des Himmels« werden ${ }^{131}$.

Die Kreuzzeitung griff diese Deutung auf, indem sie das Leben der Königin mit eingängigen christlichen Lichtmetaphern ${ }^{132}$ umschrieb und die Denkmalenthüllung zur Epiphanie verklärte, indem Luise die "Schule des Kreuzes« habe durchlaufen müssen, bevor sie nun »wiedererscheine«, so daß ihr Todeskünftig als ihr »Auferstehungstag« begangen werden könne ${ }^{133}$. Loyalitätsgenerierend sollten damit sowohl in der Ansprache als auch im publizierten Bericht Versatzstücke eines traditionellen Luisenkultes wirken. Dieser resultierte nach Luises frühem Tod 1810 nicht nur aus einer langjährigen monarchisch-offiziösen Bildpolitik, die die "Bürgertumsnähe« und gleichzeitige "Heiligkeit» der Luise zelebriert hatte ${ }^{134}$. Die kultische Verehrung war daneben auch ungelenkter Massentrauer um eine Figur entsprungen, deren Vita als Reflex des preußischen Opfer «- und Niedergangs gelten konnte ${ }^{135}$.

Das längst etablierte Sinnstiftungssystem um die Figur erhielt nun anläßlich der Oranienburger Feier kaum neue Deutungsimpulse, sondern stellte ganz auf die Reaktivierung vorhandener Kultmuster ab. Die Initiative außerhalb des unmittelbaren königlichen Umfeldes und der Aufstellungsort weitab der großen Repräsentationszentren in der Residenzstadt zeugten jedenfalls kaum davon, daß die kultische Begeisterung während der ersten Jahrhunderthälfte wiederholbar war. Zugleich zeigte sich, daß die ikonographische und semantischrhetorische Tradition dieses Kults nur bewahrt werden konnte, wenn Parallelen der »Heiligenvita « zur Entwicklung Preußens seit den Befreiungskriegen vermieden wurden: Die bürgerlichen Stifter aus Oranienburg versuchten im nachrevolutionären und reaktionären Preußen nicht, die Schutzpatronin der Befreiungskriege um den Schutz (vor)revolutionärer Freiheitstraditionen anzurufen, sondern gelangten nur über den historischen Zeitsprung in ihre unmittelbare Gegenwart. Die »Verbindung der Zeiten« und »Continuität in der Ge-

${ }^{131}$ Vgl. ibid. Bl. 63.

${ }^{132} \mathrm{Vgl}$. ibid. Bl. 62-65.

${ }^{133} \mathrm{Vgl}$. NPKZ, s.o.

${ }^{134}$ Vgl. Holger SIMON, Die Bildpolitik des preußischen Königshauses im 19. Jahrhundert. Zur Ikonographie der preußischen Königin Luise (1776-1810), in: Wallraff-Richartz-Jahrbuch (WRJ) 60 (1999) S. 231-262.

${ }^{135}$ Vgl. Wulf WULFING, Die heilige Luise von Preußen. Zur Mythisierung einer Figur der Geschichte in der deutschen Literatur des 19. Jahrhunderts, in: DERS., Jürgen LINK (Hg.), Bewegung und Stillstand in Metaphern und Mythen. Fallstudien zum Verhältnis von elementarem Wissen und Literatur im 19. Jahrhundert (Sprache und Geschichte, 9), Stuttgart 1984, S. 233-275; Günter DE BRUYN, Königin Luise, in: FRANÇOIS, ScHULZE (Hg.), Deutsche Erinnerungsorte Bd. 2, S. 286-298; Ulrike KRENZLIN, Eisernes Kreuz oder Preußenadler: ja oder nein? Zur Vorgeschichte der Diskussion um die Symbole auf dem Brandenburger Tor, in: ENGEL, RIBBE (Hg.), Hauptstadt Berlin, S. 101-114, hier S. 111112. 
schichte des Vaterlandes ${ }^{136}{ }^{13}$, die die Kreuzzeitung als Wirkeffekt der Denkmalerrichtung beschrieb, war nur um den Preis einer solchen sprunghaften, äußerst selektiv konstruierten »Continuität« zu erreichen.

Am Ende bestätigte das Berliner Luisendenkmal nicht nur die reaktionäre, sondern auch eine Preußen-zentrierte Deutungsdominanz der öffentlichen Monumente. Während etwa die Walhalla oder der Kölner Dombau in Deutschland bereits vor 1871 deutlich erkennbar gemacht hatten, daß auch die einzelstaatlichen Monarchien an der Idee einer deutschen Nation als Kulturgemeinschaft festhielten, ohne allerdings politische Einung zu betreiben ${ }^{137}$, entfiel im $\mathrm{Zu}$ sammenhang mit den preußischen Monarchendenkmälern jeder Hinweis auf einen überpreußischen Nationszusammenhang. Vor allem kam hier die nationale Bewegung mit ihrer Zielutopie der politisch geeinten Nation unter im einzelnen noch zu definierenden staatsrechtlichen und politischen Prämissen programmatisch nicht zum Zuge.

\section{London: Kompensierter Monarchiekult um den Prince Consort: Fortschrittsoptimismus und konzeptionelle Diskussion}

In Großbritannien blieben anders als in Deutschland und Frankreich Denkmäler der seit 1837 regierenden Queen Victoria bis in die letzten Dekaden des Jahrhunderts hinein zunächst eher spärlich. Diese monumentale Absenz der Monarchin war Teil jenes - im europäischen Vergleich - kultischen Defizits, das die britische Monarchie bis zu diesem Zeitpunkt auch im Hinblick auf andere öffentliche Zeremonien prägte ${ }^{138}$. Sie erschien allerdings vor allem in London in doppelter Hinsicht symbolisch kompensiert: Zum einen dominierten hier bereits etliche Monarchendenkmäler den öffentlichen Raum ${ }^{139}$, zum anderen entstanden Anfang der 1860er und während der 1870er Jahre insgesamt drei Denkmäler für den Gemahl Queen Victorias und Prince Consort, Albert, die für die zahlreichen landesweit errichteten Albert-Monumente ${ }^{140}$ nach des-

${ }^{136}$ NPKZ, 22. Juni 1858, S. 1.

${ }^{137}$ Vgl. Manfred HANISCH, Nationalisierung der Dynastien oder Monarchisierung der Nation? Zum Verhältnis von Monarchie und Nation in Deutschland im 19. Jahrhundert, in: Adolf BIRKE, Lothar KETTENACKER (Hg.), Bürgertum, Adel und Monarchie. Wandel der Lebensformen im Zeitalter des bürgerlichen Nationalismus, München u. a. 1989, S. 71-91, hier S. 74-75.

${ }^{138}$ Vgl. CanNadine, The context, u. a. S. 124.

${ }^{139} \mathrm{Vgl}$. dazu Kapitel II im zweiten Teil.

${ }^{140}$ Landesweit entstanden bis etwa 1890 ungefähr 20 Statuen in England, Schottland, Wales und Irland, von denen einige die Queen selbst in Auftrag gab; vgl. Elisabeth Susan DARBY, Statues of Queen Victoria and Prince Albert. A study in Commemorative and Portrait 
sen frühem Tod 1861 durchaus repräsentativ erschienen und deren Entstehung sich nicht selten einer unmittelbaren Involvierung Victorias verdankte. Der Rekurs auf die Nation blieb, gemessen an den deutschen oder französischen Gegenstücken, im Rahmen der Denkmalinitiativen für Albert ebenso mittelbar wie konstitutiv und prägte zuletzt auch ihre öffentliche Rezeption.

Die Initiative zu einem Prince Consort-Denkmal 1863 im Londoner Stadtteil South Kensington bezog sich von Beginn an auf Alberts Rolle als Motor und Koordinator der Londoner Weltausstellung von 1851, die mit am Ende knapp sechs Millionen Besuchern und etwa 13.000 internationalen Ausstellern in Joseph Paxtons architektonisch eigenwilligem Crystal Palace zu einem bleibenden, bis weit in die zweite Jahrhunderthälfte hineinwirkenden Erfolgsereignis geworden war $^{141}$. Zwei Jahre nach dem Ende der Ausstellung keimte die Idee zum Zeichen der "gratitude of the British nation for the eminent services rendered (...) to the industrial and commercial interests of the community ${ }^{142}$ in den Reihen der City of London auf, stieß aber durchaus auf geteilte Resonanz, die im Gegensatz zu Deutschland und Frankreich zur gleichen Zeit hier nun auch publizistisch explizit gemacht werden konnte. Die Times quittierte das Vorhaben des Lord Mayor von London, Challis, mit harscher Kritik. Sie veröffentlichte einen Leserbrief, in dem die Denkmalehrung zu Lebzeiten als verfrüht zurückgewiesen und empfohlen wurde, dem Prince Consort ganz in dessen eigenem Sinne maximal Mitsprache an einem nicht für seine Person bestimmten Monument einzuräumen ${ }^{143}$. Schließlich bezichtigte sie Challis, die Denkmalinitiative aus Gründen persönlichen und politischen Kalküls zu einem Zeitpunkt zu lancieren, zu dem sich die Corporation of London massiven Mißwirtschaftsvorwürfen ausgesetzt sah, mit deren Klärung eine parlamentarische Untersuchungskommission begonnen hatte ${ }^{144}$. Die Denkmalinitiative wurde hier mehr der kompensatorischen Befriedigung politischer Eitelkeiten sei-

Statuary, 1837-1924, 2 Bd.e, London 1983, unveröff. Ms, S. 194, 215; DIES., SMTTH, The cult of the Prince Consort, S. 58-84; Margaret HOMANS, Royal representations. Queen Victoria and British Culture, 1837-1876, Chicago und London 1998, S. 157-172.

${ }^{141} \mathrm{Vgl}$. Jeffrey A. AUERBACH, The Great Exhibition of 1851: a nation on display, New Haven und London 1999; Hermione HOBHOUSE, Prinz Albert und die Weltausstellung von 1851, in: Wilfried ROGASCH (Hg.), Victoria \& Albert. Vicky \& the Kaiser. Ein Kapitel deutsch-englischer Familiengeschichte, Ostfildern-Ruit 1997 (AK Berlin), S. 87-97; Richard D. ALTTCK, The shows of London, Cambridge, Mass., London 1978, S. 455-469.

${ }^{142}$ The Times, 28. Oktober 1853, S. 7. Das Londoner Denkmal zählte damit zugleich zu einem der frühesten Albert-Monumente, die landesweit zustandekamen. $\mathrm{Vgl}$. zum am 2. August 1865 eingeweihten Denkmal im walisischen Tenby [An.,]: An account of the welsh memorial erected to His Royal Highness the Prince Consort, as a mark of loyalty to her Most Gracious Majesty the Queen, and of an affectionate respect and gratitude to the memory of Albert the Good, Tenby 1866.

${ }^{143} \mathrm{Vgl}$. The Times, 1. November 1853, S. 7.

${ }^{144}$ Vgl. The Times, 2. November 1853, S. 8. 
tens der Metropole und ihres Bürgermeisters als einer genuinen Popularität des Prince Consort zugeschrieben.

Demgegenüber lobte das Art Journal das Vorhaben, das nun endlich von der Tradition der Denkmalsetzung nur für die »brave generals and gallant admirals« abrücke und allmählich das Verdienst derer ehre, die sich mindestens ebensosehr um das "true interest of the kingdom« verdient gemacht hätten. Als zivile Qualifikation des Prince Consort im Dienst der Nation wurde hier die Beförderung des Wohlstands aller Klassen im Volk und die Verbesserung der Lage von Industrie und Kunst gehandelt ${ }^{145}$. Mit dem Hinweis auf die bereits fünf für den Duke of Wellington gestifteten Denkmäler erklärte das Journal schließlich auch den Einwand der Times gegen eine Monumentalisierung von Personen noch zu deren Lebzeiten für obsolet ${ }^{146}$.

Den Lord Mayor hatte gleichwohl die publizistische Kritik erreicht, so daß er sich anläßlich einer ersten Sitzung der Initiatoren im Londoner Mansion House bemühte, Zweifel an der Lauterkeit seines Projekts zu zerstreuen. Daß der Prince Consort im Zuge der Weltausstellung "peace, love, and ready assistance (...) between the nations of the earth « befördert, zu einer "peaceful rivalry and competition in arts and industry in which various nations were engaged « angeleitet und dazu schließlich »our countrymen of all classes« versammelt habe, schien allmal denkmalwürdig ${ }^{147}$. Produktive Konkurrenz und Pazifismus nach außen und gesellschaftliche Homogenisierung angesichts vielfältiger Leistungsfähigkeit im Innern bezeichneten demnach die zukunftsträchtigen Effekte der Great Exhibition für die britische Nation, an die ein Denkmal erinnern würde.

Dennoch blieben Teile der Presse wie die Times distanziert. Weil affektionsund interessenfreie Motive der Stifter und eine unstrittige, vollendete Vita des Geehrten als zentrale Kriterien öffentlicher Denkmalsetzung veranschlagt wurden, fiel der Kommentar zum Projekt reichlich spitz aus: Die Monumentalisierung noch lebender Prinzen zähle zu den Usancen absoluter Monarchien, ein freier Staat hingegen tue gut daran, abzuwägen, denn eine Inflation an Symbolen verrate am Ende nur den degenerierten Zustand einer Nation ${ }^{148}$. Albert selbst beschwichtigte das Projekt zunächst mit Bescheidenheitsgesten ${ }^{149}$.

Als die Times im Frühsommer 1854 die Attacken gegen den Denkmalplan wiederaufnahm, trug sie einem öffentlichen Meinungswandel Rechnung: Unter dem Eindruck des Kriegsausbruchs auf der Krim, an dem sich nach den russisch-türkischen Konfrontationen Großbritannien seit März 1854 an der Seite

\footnotetext{
${ }^{145}$ The Art Journal 5 (1853) S. 298 und ibid. S. $303 f$.

${ }^{146}$ Vgl. ibid. S. 304.

${ }^{147} \mathrm{Vgl}$. The Times, 8 . November 1853 , S. 5 .

${ }^{148} \mathrm{Vgl}$. The Times, 9. November 1853, S. 8: "It is the sure sign of the degeneracy of a nation when it becomes lavish of symbols of honour and distinction."

${ }^{149}$ Vgl. The Morning Post, 11 . Juni 1863, S. 5; The Times, 20. Mai 1854, S. 9.
} 
Frankreichs beteiligte und gegen Rußland und seinen als orthodox und despotisch angefeindeten Zaren stellte, hatte die Popularität des Prince Consort schweren Schaden genommen. Die Zögerlichkeit der Regierung unter Lord Aberdeen und der Rücktritt des Innenministers Palmerston im Dezember 1853, der wie zahlreiche andere Anti-Peelite Tories um Disraeli und den Earl of Derby für einen raschen Kriegseintritt und ein massives Vorgehen gegen Rußland eingetreten war, wurden einer intriganten, pro-russischen Einflußnahme des Prince Consort angelastet ${ }^{150}$. Im Winter 1853 und Frühjahr 1854 überschlug sich die britische Presse vor allem radikaler und konservativer Couleur mit entsprechenden Bezichtigungen. Dabei wurde die außenpolitische Krise im Vorfeld des Kriegseintritts genutzt, um Fundamentalkritik an der verfassungsmäßig in der Tat ungesicherten Position des Prinzen an der Seite der Monarchin und an seiner deutschen Abkunft aus dem Haus Coburg und deren vermeintlicher Unvereinbarkeit mit den Interessen der Nation zu üben ${ }^{151}$. Verfassungskonformität und vor allem indigene Zugehörigkeit schienen hier für eine Protagonistenrolle als Nationalfigur unerläßlich. Allerdings konnten diese Kriterien selbst durch die wiederholten Hinweise auf die bereits 1840 erfolgte Einbürgerung Alberts nicht überzeugend für den Prince Consort geltend gemacht werden ${ }^{152}$. Zwar blieb die Kritik auch während der folgenden Jahre virulent, sie geriet aber in den Hintergrund, nachdem das Parlament bereits Ende Januar 1854 Albert entlastet hatte und Verteidiger des Prinzen aufgetreten waren, die die Debatte als Ausbruch einer "national hypochondria« und als Offenbarungseid eines Nationalismus entlarvten, der sich zur Identitätsstiftung an dämonisierten Feindbildern abarbeiten mußte ${ }^{153}$. Daß die Hinweise auf die Verdienste des Prince Consort um die Weltausstellung bei der langfristigen

${ }^{150} \mathrm{Vgl}$. als Summe der Debatte aus zeitgenössischer Perspektive Sidney Godolphin OSBORNE, Briefe vom 16. Dezember 1853 und 26. Januar 1854, in: Arnold WHTTE (Hg.), The letters of S.G.O., a series of letters on public affairs (..) published by the Times $1844-1888, \mathrm{Bd}$. 2, London o. J., S. 334-338. Vgl. Charles GREVILLE am 15., 16., 21., 25., und 29. Januar 1854, in: The GREVLLLE Memoirs. A Journal of the reigns of King George IV, King William IV and Queen Victoria by the late Charles C.F. GREVILLE, hg.v. Henry REEVE, London 1888, Bd. 6, S. 127-133. Vgl. zur Debatte bereits Johannes PAULMANN, 'Germanismus` am englischen Hof, oder: Warum war Prinz Albert unpopulär?, in: Peter ALTER, Rudolf MUHS (Hg.), Exilanten und andere Deutsche in Fontanes London, Stuttgart 1996, S. 387-415 und Richard WILLIAMS, The contentious crown. Public discussion of the British monarchy in the reign of Queen Victoria, London 1997, S. 93-106.

${ }^{151} \mathrm{Vgl}$. The Morning Advertiser vom 20. Januar 1854, in: [William CONINGHAM,] Lord Palmerston and Prince Albert. Letters by William Coningham, Esq., together with the "supressed pamphlet« entitled »Palmerston: what has he done?«, by »one of the people«, London 1854, hier S. 5.

$152 \mathrm{Vgl}$. The Times, 17. Januar 1854, S. 7.

${ }^{153}$ Vgl. F. AIRPLAY, Prince Albert. Why is he unpopular?, London 1856, hier S. 4 und $21 \mathrm{f}$ : "[Albert] is a foreigner, and, from the earliest age of English history, gullibility regarding the deceit and danger of foreigners has been a national disease. « 
Rehabilitierung seiner Person eine zentrale Rolle spielten ${ }^{154}$, spiegelte auch die Denkmalsetzung deutlich wider.

Angesichts der bescheidenen oder unterbliebenen öffentlichen Inszenierung der meisten Denkmäler der 1850er und 1860er Jahre mußte das Zeremoniell um die Einweihung des Monuments für Prince Albert in den Royal Horticultural Gardens in South Kensington umso eindrucksvoller erscheinen. In der Tat betrieb die Royal Horticultural Society als Denkmalstifter einen bis dahin ungekannten Festaufwand: Am 10. Juni $1863^{155}$ sollte ein Prozessionszug mit fast 300 Teilnehmern die Nation visualisieren, die sich hinter dem Andenken an den Prince Consort scharte und dabei namhafte Persönlichkeiten aus staatlicher, regionaler und metropolitaner Politik und Gesellschaft einschließlich der Vertreter von Regierung und Opposition sowie der anglikanischen Staatskirche und Vertreter des Militärs, nicht aber Truppenformationen einbegriff ${ }^{156}$. Mit der Enthüllung des Denkmals unter Trompetenklang und Salutschüssen der Artillerie im nahe gelegenen Park und einem striumphal march" ergänzten später Versatzstücke eines militärischen Zeremoniells die Feier ${ }^{157}$. Präsentiert wurde aber entsprechend der ausdrücklichen Aufforderung, in offiziellen Amtstrachten und Roben zu erscheinen ${ }^{158}$, eine gleichermaßen von $m$ military and naval uniforms« wie von »civic robes« geprägte, hierarchische Gesellschaft $^{159}$.

Die Queen, seit dem Tod ihres Gatten in einem Maße öffentlichkeitsscheu und zurückgezogen lebend, das allmählich Kritik zu wecken begann, hatte sich von der Teilnahme am Festakt dispensiert. Sie hatte allerdings nicht nur das Projekt rege begleitet und das Denkmal am Vortag der Einweihung im Kreis einiger Familienmitglieder und Vertreter der Stifter wie der Künstler inspiziert $^{160}$. Sie wiederholte diese Geste auch drei Tage nach den Feierlichkeiten im Rahmen eines Besuchs der Exhibition Buildings von South Kensington, und der Telegraph feierte diesen kurzfristig angekündigten und dennoch von

154 Vgl. ibid. S. 65-68.

${ }^{155} \mathrm{Vgl}$. zum Folgenden Uncovering of the Memorial of the Exhibition of 1851 on the $10^{\text {th }}$ June 1863, in: Royal Horticultural Society Proceedings, Bd. 3 (1863) S. 265-272, hier S. 265-269; The Daily Telegraph, 11. Juni 1863, S. 3; Reynold's Newspaper 14. Juni 1863, S. 1 .

${ }^{156}$ Der Prozession folgten u. a. über 100 Bürgermeister und Vertreter der Städte, in denen 1851 lokale Denkmalkomitees gebildet worden waren, in ihren regionalen Amtstrachten, dazu 16 Mitglieder der Society of Arts und weitere sieben anderer wissenschaftlicher Vereinigungen, 19 königliche Commissioners der Weltausstellungen von 1851 und 1862, 14 Angehörige des prinzlichen »Household«, 22 Vertreter des Diplomatischen Corps, 22 Regierungsmitglieder unter der Führung Gladstones, Russells und Palmerstons, und der von Disraeli angeführten Opposition, einschließlich des Archbishop of Canterbury.

${ }^{157} \mathrm{Vgl}$. Uncovering of the Memorial, S. 272.

${ }^{158} \mathrm{Vgl}$. The Times, 27. Mai 1863, S. 9.

${ }^{159}$ Vgl. am ausführlichsten die Morning Post, 11. Juni 1863, S. 5.

${ }^{160}$ Vgl. The Daily Telegraph, 10. Juni 1863, S. 5 
zahlreichen Zuschauem entlang der Zufahrtsstraße zu den Horticultural Gardens beobachteten Auftritt voreilig als definitiven wreturn of the Queen to public life and to the accustomed intercourse with her loyal subjects ${ }^{161}$. Damit erschien die Denkmalerrichtung nicht nur als Gelegenheit zur Loyalitätsbekundung seitens der Festgesellschaft gegenüber der Krone, sie wurde nach langjähriger Abstinenz zur Reaktivierung eben dieser Funktion genutzt, die das persönliche Erscheinen der Monarchin offenkundig hatte.

Festredner wie der Honorarsekretär des Exekutivkomitees Godwin blendeten alle Kritik am Prince Consort aus und konzentrierten sich auf die Programmatik, die das Denkmal mit hinreichender Deutlichkeit im eigens zitierten Inschriftenkorpus veranschaulichte. Demzufolge machte die von Albert mit initiierte Weltausstellung die Potentiale nationaler Wissenschaften, Künste und "national characteristics« produktiv nutzbar und ermöglichte gleichsam Wertschöpfung aus der eigenen nationalen Vergangenheit heraus ${ }^{162}$. In dieser Kombination aus gesicherter Eigentradition und ihrer fortschrittsorientierten Anverwandlung lag auch hier wieder die besondere Dimension des mit Albert assoziierten Nationsbegriffs. Indem Godwin es nicht an Reverenzerweisen gegenüber der Krone seitens der »loyal and loving people« fehlen ließ, bezog er die gesamte Monarchie in die Sinnstifterrolle zugunsten des skizzierten $\mathrm{Na}$ tionenkonzepts mit ein. Alberts politische Voten im Rahmen öffentlicher Debatten ${ }^{163}$ blieben um der Idee der überparteilichen Kultfigur willen unerwähnt.

Für diese offiziöse Lesart war vor allem in der liberalen Presse durchaus $\mathrm{Zu}$ stimmung zu erhalten. So wertete der Daily Telegraph das Denkmal als monumentales Zeugnis dafür, daß sich die britische Nation nicht länger nur als maritime oder koloniale Großmacht, sondern auch als Hort zivilisatorischer Errungenschaften, materiellen Wohlstands und industrieller Kompetenz profiliert hatte ${ }^{164}$. Kritik an der Festpraxis war dennoch unüberhörbar. Ebenso unmißverständlich wurde nämlich klargestellt, daß im Festarrangement von 1863 offenbar nicht an die Vision einer egalitären Gesellschaft gedacht war, sofern es sich bei der Denkmaleinweihung um eine "ceremony of no common interest«, unter Ausschluß der »ordinary crowd« handle. In der Tat blieb das Terrain zumindest während der Zeremonie einer handverlesenen "society« vorbehalten ${ }^{165}$ und stand erst nach Abfahrt der Ehrengäste auch einem größeren $\mathrm{Pu}$ blikum offen ${ }^{166}$. Daher wurde der private Denkmalstandort in den Horticultural

${ }^{161} \mathrm{Vgl}$. ibid. 13. Juni 1863, S. 5.

${ }^{162} \mathrm{Vgl}$. Uncovering of the Memorial, S. $270 \mathrm{f}$.

${ }^{163} \mathrm{Vgl}$. Hermione HoBHouSE, The Monarchy and the Middle Classes: The role of Prince Albert, in: BIRKE, KETTENACKER, Bürgertum, S. 53-69.

${ }^{164}$ Vgl. The Daily Telegraph, 11. Juni 1863, S. 4.

${ }^{165} \mathrm{Vgl}$. dazu und zum folgenden The Daily Telegraph, 11. Juni 1863, S. 3.

${ }^{166}$ Reynold's Newspaper, 14. Juni 1863, S. 1, sprach von 20.000 Denkmalbesuchern. Lloyd's Weekly, 14. Juni 1863, S. 7, und die Times, 11. Juni 1863, S. 11, schätzten mehr als 10.000 Besucher. 
Gardens prinzipiell bemängelt: »It is true that the site of the Memorial deprives it of the first necessity of a national monument - accessibility. The statue (...) ought to belong to the people ${ }^{167}$. Dieses Defizit nicht-öffentlicher Aufstellung wog selbst gegenüber dem Argument noch schwer, daß das Gelände 1851 in der Tat der Royal Commission of 1851 gehört hatte und die Standortwahl einem ureigenen Wunsch des Geehrten entsprach. Der Telegraph betonte so sehr den kontraproduktiven Effekt des exklusiven Ortes und das Erfordernis öffentlicher Nahbarkeit als konstitutives Kriterium für ein Nationaldenkmal, daß dessen Errichtung emeut auszustehen schien: »the real national memorial, which is to perpetuate the Prince and all the story of his pure and noble life, is yet to be set up, and will undoubtedly belong to the people, in position as well as by sympathy ${ }^{168}$.

Als eines der großen in der working class populären Sonntagsblätter trieb Lloyd's Weekly Newspaper die Kritik in die gleiche Richtung voran. Ein Preis von 30 Schillingen für die Eintrittskarten minderte demnach den eigentlichen Effekt des Festes ${ }^{169}$. Denn den »national event « begingen nur die »brilliant crowds«, »the cream of London society«, während die "vulgar people« ausgegrenzt blieben ${ }^{170}$. Unter diesen Bedingungen mißriet die national intendierte Feier zur Farce: Die Nation sollte eine »bright page of her history « memorieren, ihr Denkzeichen aber blieb ithe property of the Horticultural Society《; das Monument war den "wonderful accomplishments of industry« gewidmet, "but not within ken of the industrious ${ }^{171}$. Um die Sinnstiftung als grob selektiv $^{172}$ zu entlarven, dekonstruierte Lloyd's Weekly die Feierszene, indem es den Pomp der hierarchisch geordneten und erlesenen Festgesellschaft mit der Frage nach denen konfrontierte, die »absent « waren: »there was not a workman's eye beheld the scene, save that of the man who drew the cords, and (...) hurried into obscurity ${ }^{173}$. Die illusionäre Rhetorik der elitären Versammlung wurde hier mit einem politisierten Nationsbegriff unterlaufen, der auf die soziale Ungleichheit der Gesellschaft verwies, das Unrecht der Exklusion beklagte und selbstbewußt Eigenleistung und Verdienst der »workmen« betonte. Die liberale und linke Kritik der Presse setzten einer öffentlichen Rezeption

\footnotetext{
${ }^{167}$ The Daily Telegraph, 11. Juni 1863, S. 4.

${ }^{168}$ Ibid.

${ }^{169}$ Vgl. Lloyd's Weekly Newpspaper, 14. Juni 1863, S. 7; The Manchester Guardian, 11. Juni 1863, S. 3; Reynold's Newspaper, 14. Juni 1863, S. I; The Morning Post, 11. Juni 1863, S. 5.

${ }^{170} \mathrm{Vgl}$. Lloyd's, ibid. S. 8.

${ }^{171}$ Ibid.

172 Vgl. ibid.: "The thing is indeed, very select."

${ }^{173} \mathrm{Vgl}$. ibid
} 
des national intendierten Monuments im Sinne seiner Stifter erheblich enge Grenzen ${ }^{174}$.

Städtischer Initiierung verdankte sich dann eine weitere Londoner AlbertStatue $^{175}$, die Anfang Januar 1874 am Holborn Circus nahe der City, am westlichen Ende des Holborn Viaduct eingeweiht wurde. Sie schien mit einem Aufwand inszeniert, der einerseits die Feier von 1863 imitierte, indem Zeremonieelemente wie die Festprozession kopiert wurden, andererseits aber vom Festmuster abwich, sofern jetzt die Repräsentanten der City dominierten ${ }^{176}$. Die Feier trug ganz die rituelle Handschrift der City, die es verstand, mit der Route eines Festzugs die Guildhall zum Ausgangs- und Endpunkt des Zeremoniells zu stilisieren und mit zahlreichen im Ornat erschienenen Amtsträgern der City of London Corporation ein eindrucksvolles Bild metropolitaner Würde zu vermitteln. Die kurzen Festansprachen setzten denselben Akzent, wenn etwa der Lord Mayor das Denkmal ebenso als traditionales Bekenntniszeichen wie als eine Loyalitätsgeste der selbstbewußten Kapitale gegenüber der monarchischen Nation auswies ${ }^{177}$. Die Prinzenfigur rückte dabei erneut in die Nähe Queen Victorias, der die respektvolle Huldigung eigentlich galt ${ }^{178}$. Ein dezidiert hauptstädtischer und ein genauso nachdrücklicher landesweiter Albertund Monarchiekult wurden auf diese Weise subtil verquickt.

Den Abschluß des Denkmalkults um den Prince Consort markierte schließlich eine monarchisch-offiziöse Stiftung, die - bildprogrammatisch und konzeptionell ausgefeilter als alle Londoner Monumente zuvor - weit hinter dem rituellen Standard zurückblieb, den die städtischen Initiatoren gesetzt zu haben schienen. Entgegen anfänglicher Planungen seit Mitte der 1860er Jahre richteten die monarchienahen Denkmalstifter keine große öffentliche Grundsteinlegungsfeier aus ${ }^{179}$. Auch ergänzte man die Kolossalstatue des Prinzen 1876

${ }^{174}$ Die konservative Presse urteilte zustimmender. Vgl. The Morning Post, 11. Juni 1863, S. 5; The Standard 11. Juni 1863, S. 3.

${ }^{175}$ Vgl. Papers relating to the Prince Consort Memorial, Holborn Circus, c. 1872-4. Mit einem zwischenzeitlich 1864 noch errichteten Albert-Denkmal in der Old Kent Road südlich der Themse (von Thomas Earle) hatte man von Beginn an nicht auf eine gesamtnationale Reichweite spekuliert. Vielmehr zielte die initiierende Licensed Victuallers' Association zur Sozialfürsorge für verarmte Gastwirte auf eine Reverenz an den Patron dieser Institution in Kennington. Vgl. The Daily Telegraph, 10. August 1864, S. 3. Das Denkmal wurde 1958 nach Berkshire verlegt, vgl. BLACKWOOD, London's Immortals, S. 60.

${ }^{176} \mathrm{Vgl}$. zum Folgenden The Daily Telegraph, 9. Januar 1874, S. 3; ibid. 10. Januar 1874, S. 2; The Times, 9. Januar 1874, S. 9; The Evening Standard, 9. Januar 1874, S. 5; Lloyd's Weekly Newspaper, 11. Januar 1874, S. 7; The Standard, 10. Januar 1874, S. 3 und The Times, 4. Oktober 1873, S. 5.

${ }^{177}$ Vgl. The Daily Telegraph, ibid.

${ }^{178} \mathrm{Vgl}$. ibid.: "I am well pleased to be able to say that I believe Her Majesty the Queen is respected by all nations abroad, and I am sure - and I affirm it with emphasis - that Her Majesty is loved and esteemed by all at home.« Vgl. auch Reynold's Newspaper, 18. Januar $1874, \mathrm{~S} .2$.

${ }^{179}$ Vgl. The Times, 16. Mai 1864, S. 9. 
ohne Zeremoniell ${ }^{180}$. Die Queen würdigte das Denkmal flüchtig mit einer kurzen Visite am Hyde Park, während in den folgenden Tagen gelegentlich spontan größere Zuschauergruppen zusammenkamen ${ }^{181}$. Die unspektakulärschleichende Weise, in der das Denkmal ohne symbolische Initialakte im öffentlichen Raum zu stehen kam, erklärte sich nicht zuletzt aus dem Umstand, daß seine langwierige Genese während ausgedehnter Debatten um die Form des Monuments von nachlassendem Interesse der Öffentlichkeit begleitet worden, mithin deutlicher Symbolverschleiß eingetreten war.

Auch ohne Festakte trat aber die nationale Ambition der Denkmalstifter ebenso zutage, wie die von der Presse unternommenen Versuche, einen spezifisch britischen Nationsbegriff zu entwerfen. Eine am Beginn der Initiative des Lord Mayors und führender städtischer Aldermen, Bänker und Händler der City stehende öffentliche Resolution vom Januar 1862 ließ zunächst erkennen, daß mit dem Denkmal der nach dem frühen Tod des Prinzgemahls unter Schock stehenden Öffentlichkeit gleichsam monumentale Trauerarbeit ermöglicht werden sollte ${ }^{182}$. Ins Zentrum der Gedächtnisstiftung rückten daher einmal mehr Alberts "great abilities (...) devoted to improving the condition of the humbler classes, to the development and extension of science an art $(\ldots) \aleph^{183}$. Alberts Engagement zielte mithin auf eine kulturell und wissenschaftlich entwickelte nationale Gemeinschaft, die als durchaus ungleicher Gesellschaftsverband auf Intervention zugunsten der sozial Schwächeren angewiesen blieb. Ähnlich begründete Lord Mayor Cubitt das Monument mit dem Einsatz des Prince Consort sfor the improvement of all our social institutions, and ameliorating the condition of the working classes ${ }^{184}$. In der Zuordnung der Kultfigur zum simprovement« als einem prominenten politischen Schlüsselund programmatisch wie moralisch hoch aufgeladenen Erwartungsbegriff des Jahrhunderts eröffnete Cubitt ein weites Bedeutungsfeld und verband die Figur bei allem nach wie vor dringlichen Reformbedarf vor allem mit dem Stolz über wachsenden Wohlstand und politisch-administrative und soziale Modernisierung ${ }^{185}$. Für den Bischof von London schließlich verkörperte Albert den pflichtbewußten "Englishman «, dessen Verantwortung allerdings in quietistischer Manier nicht mit dem Willen zur Veränderung, sondem unter Wahrung des als gottgegeben definierten Platzes in der Gesellschaft wahrgenommen

${ }^{180}$ Vgl. The Times, 13. März 1876, S. 8.

${ }^{181}$ Vgl. ibid.

${ }^{182} \mathrm{Vgl}$. The Times, 15. Januar 1862, S. 9; At a public meeting held at the Mansion House on the $14^{\text {th }}$ of January, 1862, in: [An.,] Proposed National Memorial, S. 2-3, hier S. 3.

${ }^{183} \mathrm{Vgl}$. At a public meeting, ibid. S. 2 und The Times, 15. Januar 1862, S. 9.

${ }^{184}$ At a public meeting, S. 3.

${ }^{185}$ Vgl. BRIGGS, The Age of improvement, S. 1-3 und S. 435-445; Boyd HIITON, The age of atonement. The influence of Evangelicalism on social and economic thought, 1795-1865, Oxford 1988, S. 17 
werden solite ${ }^{186}$. Damit schloß er indirekt die Forderung nach sozialer Statusverbesserung oder den reformerischen Impetus zur Einebnung sozialer Hierarchien aus. Daß das Denkmal schließlich als öffentliches Zeugnis der Loyalität mit der Monarchie aufzufassen sei, war inzwischen unverkennbar zum verbindlichen Topos der Albertdeutungen avanciert ${ }^{187}$.

Umso mehr bemühte man sich um eine definitive öffentliche Rehabilitierung des Prince Consort, dessen Rolle seit den erbitterten Polemiken während der $1850 \mathrm{er}$ Jahre umstritten geblieben war. Nunmehr bescheinigte man ihm, durch sein intensives Studium der "laws" und »institutions" faktisch ein "Englishman" geworden zu sein ${ }^{188}$, so daß die aktive Aneignung der konstitutionellen Tradition des Landes hier als Prämisse für die Zugehörigkeit zur englischen Nation galt. Die Times schließlich grenzte den solchermaßen umrissenen von einem kontinentalen Nationsbegriff ab, der mit Autokratietendenzen und einem grundlegenden Liberalismusdefizit gleichgesetzt wurde:

On a continental field the gifted and energetic member of a Royal House can gratify his love of business (...) better by affecting autocratic energy than by using the language of Liberalism. But Prince Albert was in a very different position. Every British Prince must, more or less, accomodate himself, to the feelings of the country, which reject all attempts at dictation. (...) he seems to have discerned with unerring judgment the genius of our institutions, (...) and that particular path in which alone he could safely display his talents and energy ${ }^{189}$.

Daß Albert zur nationalen Kultfigur hatte avancieren können, setzte mithin eine Adaption freiheitlicher Werthaltungen und institutionell garantierter Rechtstraditionen, am Ende die vollständige Umorientierung zugunsten jenes Sonderwegs ("particular path «) nationaler Identitätsbildung voraus, auf dem die Times Großbritannien emphatisch wähnte. Im Blick auf das neue Denkmal behauptete sie hier eine Fundamentaldifferenz zwischen kontinentaler und insularer Nationsidee und sah allein die britische Nation in traditionellen Freiheitswerten verankert.

Den programmatischen Kommentaren traten konzeptionelle Diskussionen zur Seite, in denen nicht anders als bereits im Zusammenhang mit dem ersten Albert-Denkmal das öffentliche Monument als Medium und die Frage einer geeigneten Formkonzeption problematisiert wurden. Die Idee, dem Prince Consort eine Art pädagogische Stiftung zu widmen, hatte bereits der Geistliche

${ }^{186} \mathrm{Vgl}$. At a public meeting, S. 4: "Every man can learn to do his duty well in the station to which God has called him to do it well (...) knowing also that he whom we this day mourn, if he had done nothing else, would have earned the (...) admiration of Englishmen for the simple discharge of duty in domestic life."

${ }^{187}$ Ibid.

${ }^{188} \mathrm{Vgl}$. At a public meeting, S. 5.

${ }^{189}$ The Times, 15. Januar 1862, S. 9. 
J.A. Emerton wiederholt verfochten ${ }^{190}$. Er bemängelte die anfangs erwogene Obelisk-Idee $^{191}$ und setzte sich für den Bau eines »International Temple of Peace« ein, der ein Industrie-Museum und eine Schule für Wissenschaft und Kunst beherbergen und allen »lovers of Peace of all Nations of the Earth « eine Plattform für Kommunikation und Kooperation bieten sollte ${ }^{192}$. Seine Nationsidee befrachtete Emerton so mit einem eschatologisch aufgeladenen Pazifismus ${ }^{193}$, Modernisierungshoffnungen und sozialen Homogenisierungserwartungen.

Gegen die Obelisk-Idee optierten auch andere Diskutanten mit dem Argument, daß eine imitierte ägyptische Formgebung an der dezidiert christlichen Konnotation der Prinzen-Figur vorbeiziele ${ }^{194}$. Sobald sich das Komitee im Einverständnis mit Queen Victoria im April 1862 endgültig vom Obelisk-Plan abgewandt hatte ${ }^{195}$, lebten die bis dahin verdrängten Alternativkonzeptionen noch einmal auf. Wiederholt wurde für karitativ-pädagogische Einrichtungen wie Modellsiedlungen im Außenbezirk der Metropole für eigens ausgewählte "poor people of good character « plädiert ${ }^{196}$. Ähnlich motiviert war der Plan für ein »Royal Hospital for poor and decayed men \& women and for the reception of children of a tender age ${ }^{197}$. Noch eindringlicher am pädagogischen Vermächtnis des Prinzen orientiert blieben die frühen Projekte des Direktors des South Kensington-Museum Henry Cole: Cole setzte sich für eine "Industrial University« ein, die die »Industrial Education« der »manufacturing population « verbessern, berufsspezifische Expertenqualifikationen vermitteln und mit einem eigenständig neben den etablierten Universitäten gültigen System von Prüfungspatenten aufgewertet werden sollte ${ }^{198}$. Daneben kursierte die Idee zum Bau eines Scientific College in Suffolk, die erst die »moral power« des

${ }^{190}$ Vgl. Rev. J.A. EMERTON, A second letter to the Right Honorable Earl Granville, president of the Council, on the Memorial to His Royal Highness Albert, Prince Consort, London 1862, S. 3-11.

${ }^{191}$ Vgl. Schreiben C. Greys namens der Königin an den Vorsitzenden des Denkmalkomitees und Lord Mayor von London Cubitt, 19. Februar 1862, in: [An.,] Proposed national memorial, S. 6-7, hier S. 7; The Times, 22. Februar 1862, S. 5.

$192 \mathrm{Vgl}$. EMERTON, A second letter, S. 16 und $19 \mathrm{f}$.

${ }^{193} \mathrm{Vgl}$. ibid. S. 24: $»$ To [Albert, H.R.], (...) all shall look with hope as a means of bringing about the happy time, when wars shall cease and (...) the real Emmanuel, the true $>$ Prince of Peace (...) shall reign for ever and ever.«

${ }^{194}$ Vgl. Francis Turner PALGRAVE, Modern Monoliths, in: London Review 15. März 1862, RA Vic. Add. H 1, Bl. 109-110, hier Bl. 110.

${ }^{195}$ Vgl. Schreiben Greys im Auftrag der Queen an Eastlake vom Komitee, 19. April 1862, ibid. Bl. 211.

$196 \mathrm{Vgl}$. Charles Baylis, Esq. suggesting model cottages \& baths \& workhouses for memorial, 23. April 1862, ibid. Bl. 230.

${ }^{197}$ Vgl. R. Cook an Eastlake vom Komitee, 24. April 1863, ibid. B1. 249.

${ }^{198}$ Vgl. Henry Cole, Memorial to His Royal Highness the Prince Consort, 31. Dezember 1861, RA Vic. Add. H. 2, Bl. 2 und DERS. in einem Leserbrief an die Times, 6. Januar 1862, S. 9 
Prince Consort als großer Philanthrop und nationaler Erzieher dauerhaft dokumentieren könne ${ }^{199}$.

Im Grunde stellten dergleichen Vorschläge die Aussagekraft und Sinnhaftigkeit der traditionellen öffentlichen Denkmalidee radikal infrage, indem sie eine unmittelbare pragmatische und dem Monument bereits inhärente Einlösung der vermeintlich nationalen, hier überwiegend sozialreformerischen Programmatik forderten. Politische Praxis sollte demnach ikonographische wie rhetorische Absichtserklärungen ersetzen. Bei zahlreichen Entwürfen blieb daneben die Intention bestimmend, die Pazifismus- und internationale Fortschritts- und Kooperationsidee im Geiste der Weltausstellung wiederzubeleben, wenn etwa an Säulenkonstruktionen gedacht wurde, die in Gestalt eines überdimensional breiten Sockels für zahlreiche internationale Widmungsinschriften Raum bieten sollten ${ }^{200}$, oder wenn die Innenausstattung gigantischer Säulenkörper mit Museen und Theatern erwogen wurde, die die Ausstellungsidee von 1851 gleichsam perpetuieren wollten ${ }^{201}$.

Der Intervention der Queen war es geschuldet, daß diese Alternativkonzepte am Ende zugunsten jenes Entwurfs übergangen wurden, der die unter einem reich verzierten Baldachin übergroß thronende Gestalt Alberts zeigte ${ }^{202}$. Der Architekt George Gilbert Scott beabsichtigte, durch den gotischen Stil, den der Prince Consort besonders geschätzt habe, zu einer schreinartigen Konstruktion zu gelangen, die den kultischen Gestus des Gesamtdenkmals unterstützen wür$\mathrm{de}^{203}$. Darüber hinaus legten sich die Initiatoren inschriftlich auf ein Höchst$\mathrm{maB}$ an integrativer Programmatik fest, indem sie - am Tatbestand einer eigentlich höchst exklusiven Initiative vorbei - "Queen Victoria and her people« als gleichberechtigte Stifter des "national memorial« und konstitutive Teile der Nation nannten ${ }^{204}$.

${ }^{199}$ Vgl. Rev. F.A. JoHnson, The Prince Consort Memorial. The proposed scientific College for Suffolk, shewn to be a necessity, and the carrying out of the national designs of His late Royal Highness, with the reasons why it should be generally supported, London ${ }^{2} \mathrm{o}$. J., S. 4.

${ }^{200}$ Vgl. C. Henry an Eastlake, 24. April 1862, RA Vic. Add. H 2, Bl. 248.

${ }^{201}$ Vgl. Henry Fry an Sir Charles Phipps, 12. Februar 1862, ibid. Bl. 255.

${ }^{202} \mathrm{Vgl}$. Grey im Namen der Queen an Eastlake, 22. April 1863, ibid. Bl. 438.

${ }^{203}$ Vgl. George Gilbert SCOTT, Explanatory Remarks on the designs submitted for the Memorial to His Royal Highness the Prince Consort and the proposed Hall of Science, o. J. [1863], RA Vic. Add. H. 2, Bl. 491-494, nach separater Paginierung S. 3-18, hier S. 5-6. Vgl. auch EPSILON [i.e. John BELL], That the sentiment of the statue of the Prince in the National Prince Consort Memorial should be devout, and in harmony with the sacred character of the structure it is to occupy - which is a colossal shrine - and that the statue should be of marble, and not in bronze gilt. A letter to the editor of the Journal of the Society of Arts, $\mathrm{N}^{\circ} 2, \mathrm{o} . \mathrm{O}$. o. J.

${ }^{204}$ Vgl. G.G. ScOTT, Prince Consort Memorial. Report January 1869, RA Vic. Add. H. 4, Bl. 3-53. 
In der Tat überwog in der veröffentlichten Meinung diese euphorische Rezeption des Denkmals, in der sich devote Verehrungsformeln und promonarchisches Bekenntnis mischten ${ }^{205}$. Spuren öffentlicher Kritik an der Denkmalwürdigkeit des Prince Consort und der nationalen Relevanz der Figur zeichneten sich nicht mehr ab. Eher deuteten später mehrfach Klagen über den äuBeren Verfall des Prince Consort Memorials und das Ausbleiben restauratorischer Maßnahmen seitens des Staates darauf hin, daß die Öffentlichkeit mehr als die offiziellen Denkmalstifter um die Wahrung der Symbolfunktion des Monuments bemüht schien ${ }^{206}$.

\section{Vergleich}

In Frankreich nach 1851 und Preußen-Deutschland waren es bevorzugt die starken Exekutiven, die sich den nationalen Gedanken zu eigen machten, um Loyalität für die autoritäre Herrschaft einzuwerben. Der nationale Diskurs in England war demgegenüber nicht nur erheblich stärker als auf dem Kontinent nach dem Parlament, sondern zusätzlich auch stärker zum politischen Liberalismus hin veriagert. Die schwindende Macht der Krone und eine deutlich geringere Ambition Queen Victorias selbst, sich zum Inbegriff der Nation zu stilisieren, lenkten entprechende Kultbemühungen hier verstärkt auf den Prince Consort ab.

Anders als dies für die aufwendige Inszenierung der Weltausstellungen 1855 und 1867 in Paris gelten konnte und vor allem anders als im Rahmen der vom

${ }^{205}$ Vgl. William Thomas KIME, Albert the Good. A Nation's tribute of affection. To the memory of a truly virtuous Prince, London 1862, S. 37-38; James W. DEAN, National Memorial to H.R.H. the late Prince Consort. "Treu und fest «: a poem in two books, London 1865, S. 15; [An.,] Handbook to the Prince Consort National Memorial, published by authority of the Executive Committee, London 1874, S. 3; The Times, 14. November 1873, S. 3.

${ }^{206}$ Vgl. The Times, 1. Juni 1882, S. 7; ibid. 13. Februar 1901, S. 7; Daily News, 21. März 1890; The Times vom Oktober 1901, PRO Work 20/13 [up]. Daß das Monument bis 1914 polizeilich bewacht wurde, sollte weniger dezidierte Denkmalgegner abschrecken als der Prävention gegen einen weithin unpolitischen, diffusen Vandalismus dienen; vgl. Notiz aus Whitehall an das Office of Works vom 4. Februar 1887, The Star, 7. Dezember 1889; Bericht von Scotland Yard an das Office of Works vom 17. Februar 1913, PRO Work 20/12 [up]. - Dem reduzierten monarchischen Kult mochte es geschuldet sein, daß ein Bedarf an historisch-mythischer Kontinuitätsstiftung entstand. Mit der Errichtung eines Denkmals für den mittelalterlichen Regenten und Kreuzfahrer Richard I. Löwenherz (Richard Cocur de Lion) blieb der Versuch historisierender Mythosbildung allerdings marginal. Vgl. The Times, 3. Juni 1853, S. 6; 6. Juni 1853, S. 8; 10. Juni 1853, S. 5; 7. November 1860, S. 7; The Standard, 6. Juni, S. 1; The Daily News, 6. Juni, S. 5; Charles Barry an George Russel, Esq., am 11. August 1856, PRO Work 20/28. 
Empire pompös ausstaffierten »Fête impériale« am 15. August jeden Jahres ${ }^{207}$, verzichtete Napoleon III. in der Regel darauf, öffentliche Denkmäler in der Hauptstadt aufwendig zu inszenieren und stattete die Nation eher auf dirigistischem Wege mit den von der Staatsfuihrung erwünschten Symbolen aus. Entsprechend schwach blieb allerdings selbst in einer bis in die Spätphase des Regimes weithin kontrollierten Presse das öffentliche Echo auf die Zeichensetzungen. Die Expansion der imperialen Nation sollte unterdessen nach 1848 zum neuen Thema in der Monumentlandschaft der Hauptstadt stilisiert werden, dies wie zum Zeichen für eine späte Wiedergutmachung der ersten traumatischen Niederlagenerfahrung Frankreichs aus dem frühen Jahrhundert zum einen und für einen demonstrativen Rückgriff auf die napoleonische Vergangenheit Frankreichs zum anderen. Zur Überwindung des frühen Zusammenbruchstraumas wurde gleichsam symbolisch die Reaktivierung napoleonischer Herrschaftstradition verordnet.

Im Rahmen der napoleonisch verfügten Denkmalprojekte in Paris wurde nicht anders als später in Berlin auch eine Frauengestalt in nationaler Absicht denkmalwürdig. Die Denkmalstiftung für die Kaisergattin Joséphine, die das einzige nationalpolitisch konnotierte Frauendenkmal vor dem Systemumbruch von 1871 in Paris blieb, erschien ganz der nationalen Sinnschöpfung aus der »épopée napoléonienne« untergeordnet und entbehrte jeder emanzipatorischen oder partizipatorischen Note im Blick auf ihr Geschlecht. Gleichwohl suchte man von der Weiblichkeit als nationalem Attribut zu profitieren, indem emotionalisierende und sakralisierende Sinnaufladungen stärker als auf jede männliche Kultfigur projiziert wurden. Ein ungleich höheres $\mathrm{MaB}$ an populärmythischem Assoziationsvorrat konnte demgegenüber das freilich nicht zentral, sondern im stadtfernen Oranienburg und auch nicht im Rahmen staatlicher, sondern städtischer Initiativen entstandene Luisendenkmal auf sich vereinen. Auch hier blieb die zeitgenössisch seltene Inklusion der Frau in die Riege der Denkmalwürdigen auf dynastisches Personal begrenzt und an Emotionalisierungs- und Sakralisierungsgesten gebunden. Während aber Joséphine in Frankreich als Versatzstück des Napoleon-Kults zu Ehren kam, veranschaulichte die Oranienburger Luise-Figur gerade den antinapoleonischen Impetus preußischer Nationsbildung. Joséphines Tod 1814 las sich ihren Deutem zufolge als Parabel auf den märtyrerhaften Niedergang des napoleonischen Ersten Empire, während Luise nach der Niederlage und Demütigung noch zumindest die moralische Rekonvaleszenz Preußens begleitete und damit über den Niederlagentopos hinaus die innere Regeneration der preußischen Nation bezeugen sollte, dabei aber nicht anders als ihr französisches Pendant Teil eines übergeordneten Konstrukts von Nationalgeschichte blieb, indem ihre Stif-

${ }^{207}$ Vgl. Programme officiel du 15 août, Paris o. J.; vgl. TRUESDELL, Spectacular politics, S. $136-155$. 
ter die Revolutionszäsur von 1848 im reaktionär-monarchischen Sinne verleugneten.

Der Statuenaustausch auf der Pariser Vendômesäule schließlich machte in Paris im Rahmen eines beispiellosen Verfahrens den vermeintlichen Zeugen und Begründer nationaler Kontinuität zum Kultgegenstand. Dabei eignete sich der regierende Empereur den Napoleon-Mythos an, dessen Legitimations- und populäres Konsenspotential abgeschöpft, der aber zugleich mit imperialem und bellizistischem Impetus erneuert werden sollte. Im Namen der Nation wurde nicht die Rettung revolutionärer Freiheits-Errungenschaften, sondern die Reaktivierung der »gloire militaire« zur Quintessenz der Napoleon-Erinnerung. Die monarchische Selbstinszenierung Napoleons III., die durch die Ankopplung an dieses Erbe erfolgte, blieb damit kaum weniger als die preußischen Monarchendenkmäler in Berlin weit davon entfernt, die politische Binnenausstattung der Nation jenseits ihrer Fixierung auf die Herrscherautorität zu thematisieren. Währenddessen standen in Paris wie Berlin machtpolitischautoritäre und militärische Traditionsbildung im Zentrum nationaler Sinnkonstrukte. Indem die staatliche Denkmalpolitik nicht nur in Paris bis zum Ende des Zweiten Empire um eine sorgsam kontrollierte Streuung nationaler Symbole bemüht war ${ }^{208}$, deren Einnerungswert von jeder Anknüpfbarkeit an revolutionäre Konnotationen frei sein und eng mit der politischen Ordnung und den militärischen Errungenschaften des Ersten Empire ${ }^{209}$ assoziiert bleiben sollte, und indem die staatlich dekretierte Denkmalpolitik sonst nur weitgehend unpolitische Denkmalsetzungen ${ }^{210}$ duldete, lagen die Parallelen zur Berliner Denkmallandschaft während der 1850er bis 1870er Jahre offen zutage.

Auch in Berlin begünstigte die Verdrängung des revolutionären Erbes den Rekurs auf historisches Herrschaftspersonal, an das zu appellieren opportun erscheinen mußte, um die Kontinuität einer großen Geschichte der Nation zu thematisieren. Während die Denkmalstiftung für Friedrich Wilhelm III. im Tiergarten dabei noch 1849 alle Spuren einer Verbürgerlichung trug und den Dynasten mehr mit der Metropole als mit der preußischen Nation in Verbindung brachte, entstand mit dem Friedrich II.-Denkmal Unter den Linden bis

${ }^{208}$ Der Plan, die Champs Elysées beidseitig mit einer Statuenreihe zu flankieren und so zu einer klassischen "Via Triumphalis« zu gelangen, wie sie unter spezifisch dynastischen Vorzeichen in Berlin mit der Siegesallee um die Jahrhundertwende entstand, schlug Mitte der 1850 er Jahre in Paris fehl und wurde offenbar von Napoleon III. nicht protegiert. Vgl. Uwe WESTFEHLING, J.I. Hittorffs Pläne für ein Denkmalsforum in Paris, in: WRJb 36 (1974) S. 273-294, hier u. a. S. 284f.

${ }^{209}$ Vgl. Katrin SIMONS, Vom Triumph der Republik zur Apotheose Napoleons. Überlegungen zur Ikonographie der Revolution und des Konsulats am Beispiel einiger Gemälde von Jacques Louis David und Jacques Réattu, in: WRJb 43 (1982) S. 207-230.

${ }^{210} \mathrm{Vgl}$. für Paris u. a. das Grabmonument für den jüdischen Komponisten Fromentel Halévy auf dem jüdischen Friedhof von Montmartre, Inaugurationsbericht im Artiste 5 (1. April 1864), S. 152f. 
1851 das eigentliche Antirevolutionsfanal in der metropolitanen Denkmallandschaft. Schon im vorrevolutionären Kontext war die Initiative unter unnachgiebiger Führung durch Friedrich Wilhelm III. wieder aufgegriffen und der monarchische Leitungsvorbehalt vehement selbst gegen materielle Partizipationswünsche der Provinzialstände verteidigt worden. Mit der gleichen Rigidität zog Friedrich Wilhelm IV. bereits die Inszenierung der Grundsteinlegungsfeier 1840 an sich, die allerdings ungeachtet militärischer Elemente die Nation durchaus als ständisch gegliederte Gesellschaft anvisierte und dabei auf Initiative der Stadt hin von sozialen Fürsorgemaßnahmen im Namen eines paternalistischen Königtums flankiert war. Anläßlich der Denkmaleinweihung 1851 dominierte demgegenüber das militärische und ein dezidiert preußisch-nationales Erscheinungsbild, während das ausdrückliche Verbot aller revolutionären Symbolik den Tenor der Feier vorwegnahm. Der rituellen entsprach eine programmatische Differenz: 1840 war die preußische Nation noch als Amalgam von "Volk" und "Monarch" definiert, eine inklusiv-harmonische Idee der preußisch-nationalen Gesellschaft beschworen und auf eine Traditionsbildung abgestellt worden, die sich an den Reformen des frühen Jahrhunderts orientierte. Dazu beschwor das Zitat des Befreiungskriegsmythos die Idee von der kriegsgeborenen Nation, nach der die französische Bedrohung von außen die Nation zum homogenen Verband zusammengeschweißt hatte. Demgegenüber repräsentierte der preußische Monarch 1851 nicht mehr zuerst den Friedensregenten, Mäzen und reformerischen Impulsgeber, sondern den Militärbefehlshaber. Zudem verlagerten die Denkmaldeuter das Bedrohungsszenario gleichsam nach innen und identifizierten nun die Revolutionsgegner als Kern der wahren preußischen Nation. Von der französischen Denkmalpolitik des Empereur unterschied sich das preußische Prozedere 1851 damit nicht nur durch eine deutlich aufwendigere öffentliche Inszenierung, sondern auch im Blick auf die programmatisch anvisierte machtpolitische Reichweite der Nation, die nämlich nur dem Empereur zufolge tendenziell imperiale Dimensionen annahm, während sie sich im Berliner Arrangement auf die Ausdehnung von Preußen begrenzte. Eine offiziöse Diktion allerdings, die die Nation zuerst autoritär und militärisch konnotierte, prägte durchaus beide Zuschreibungsverfahren.

Ritus und Programmatik der Einweihung Londoner Albert-Denkmäler lagen nun in mehrfacher Hinsicht quer zum französischen Inszenierungsverzicht und den deutschen Feiern. Zunächst stellten sie keine gleichrangigen Pendants zu den kontinentalen Herrscher-Monumenten dar, sondern - eher als Parallele zu den Denkmälern für Eugène, Joséphine und Luise - gleichsam sekundäre Kultfiguren, deren Errichtung anstelle monarchischer Abbilder sich aus Queen Victorias spezifischer Kultabstinenz bereits vor und allemal nach Alberts Tod 1861 erklärte. Dennoch trugen sie angesichts einer entsprechenden Involvierung der Krone die Handschrift monarchisch initiierter oder beeinflußter Sinn- 
stiftungen und bildeten insofern durchaus Versatzstücke einer auf die monarchische Staatsordnung zentrierten Inszenierung der Nation. Während selbst das große Hyde Park-Denkmal für Albert bis Mitte der 1870er Jahre lediglich zeremonielos aufgestellt wurde, entfaltete sich im Umfeld der Einweihung einer ersten Albert-Statue 1863 eine durchaus ausgedehnte Festkultur. Vor allem im Rahmen der Festprozession wurde die Nation dann als Summe metropolitaner, regionaler und staatlicher politischer und gesellschaftlicher, ziviler ebenso wie militärischer Kompetenzträger visualisiert. Zugleich blieb dieser Zug aber elitär, indem nur prominente Kunst- oder wissenschaftliche Vereine, nicht aber kleinbürgerliche Formationen wie in Berlin 1840 und 1851 vertreten waren. Klassenindifferente Homogenität und friedlich-produktive Konkurrenz sowie internationale Offenheit und Transparenz kennzeichneten das auf die Weltausstellung von 1851 fixierte nationale Selbstbild, das vor dem Projektionshintergrund der Albert-Figur geprägt wurde. Seiner ebenso pazifistischen wie globalen und schlieBlich auch auf Momente der Binnenkonstituierung der Nation abhebenden Orientierung nach schien es im deutschen wie französischen Vergleich zunächst singulär. Allerdings förderten die heftigen PopularitätseinbuBen, denen Albert unter dem Eindruck der Krimkriegkrise in den 1850er Jahren unterlag, vorübergehend eine aggressive und hermetische Exklusionspolemik zutage, in deren Zuge Albert stigmatisiert und seine nationale Zugehörigkeit in Zweifel gezogen wurde. Die öffentliche Diffamierungskampagne entlarvte die Vordergründigkeit vorheriger Inklusionsrhetoriken, blieb langfristig aber Episode.

Die Ambition, den Prince Consort nicht nur im Rahmen eines stellvertretenden Monarchiekults, sondern auch als Repräsentant der sozial kohärenten Nation zu inszenieren, bestimmte schließlich die Initiative für das große Hyde Park-Denkmal des Prince Consort. Der ehemalige Exklusions- verwandelte sich nun in einen demonstrativen Inklusionsdiskurs, in dessen Verlauf auch ein auf Albert projizierter Nationsbegriff weiter Konturen gewann. Konstitution, Liberalismus und Freiheit firmierten demzufolge als Eckwerte britischnationaler Identität und leiteten im europäischen Vergleich zur zeitgenössischen Selbstdiagnose an, einen "particular path" zivilisatorisch-freiheitlicher Nationswerdung zu beschreiten.

Im Unterschied zu Deutschland und Frankreich während der 1850er und 1860er Jahre wurden die Londoner Denkmalstiftungen verstärkt im Rahmen eines kritischen publizistischen Diskurses erörtert. In dessen Verlauf stand die Motivation von Denkmalstiftem ebenso zur Diskussion wie die prinzipielle Eignung des öffentlichen Monuments zum nationalen Kult, das bisweilen dem unumwunden geäußerten Verdacht quasi-absolutistischer Manipulation unterlag. Auch die Einweihungsfeier wurde stärker als bei deutschen oder französischen Feiern einer öffentlichen konzeptionellen Kritik unterzogen, indem liberale Zeitungen den exklusiven Aufstellungsort und die Ausgrenzung eines un- 
privilegierten Publikums als Perversion einer phrasenhaften nationalen Inklusionsprogrammatik anprangerten. Außergewöhnlich blieb im Vergleich, in welchem Maße die linke Presse den Nationsbegriff nachdrücklich politisierte, die Homogenitätsfiktionen mit dem Verweis auf die reale soziale Ungleichheit in der englischen Gesellschaft unterlief und selbstbewußt Partizipationsansprüche im Namen der von Albert verkörperten Nation anmeldete. Wiederum anders als in Deutschland oder Frankreich nahmen in England schließlich weitere Teile der publizierenden Öffentlichkeit an einer Diskussion um ein adäquates Formkonzept vor allem für das Hyde Park-Memorial teil und verrieten damit ein zeitgenössisch bemerkenswertes Sensorium für die Halbwertszeit monumentaler Zeichen, an deren Stelle daher nicht selten für karitative Einrichtungen oder Bildungsinstitutionen im Sinne pragmatisch-partizipatorischer Denkmal-Konzeptionen plädiert wurde. Ein ähnliches Problembewußtsein für die Frage nach dem Funktionieren und Wirken nationaler Symbole ließen so weder die Berliner noch die Pariser Denkmalstifter erkennen. Singulär blieb schließlich während der frühen zweiten Jahrhunderthälfte das Ausmaß, in dem auch die Stadt London sich quasi-monarchisches Personal anzueignen wußte, indem sie, eingebettet in ein aufwendiges »civic ritual«, die Prinzenfigur gleichermaßen zum Projektionshintergrund für metropolitanes Selbstbewußtsein und monarchische Loyalitätsbekenntnisse machte.

Besondere Bedeutung gewann nun angesichts der oben genannten Parallelen zwischen preußischem Monarchen- und französischem Empirekult die singuläre symbolpolitische Umtriebigkeit der republikanischen Opposition in Paris, die zwar erst in der späten Liberalisierungsphase des Zweiten Empire möglich wurde, zu der nun aber im synchronen Vergleich jedes Pendant in Berlin wie in London während der ausgehenden 1860er Jahre fehlte. Unterhalb dieser Differenzschwelle bestanden aus einer diachronen Vergleichsperspektive Verfahrensähnlichkeiten mit den gescheiterten Berliner Versuchen zur monumentalen Gedächtnisstiftung für die Märzrevolution. Die linke Opposition gegen die konservative Reaktion in Preußen 1848/49 mußte nämlich nicht anders als die französische republikanische Opposition 1868/69 gegen das autoritäre Kaiserreich auf das städtische Friedhofsareal als Ort des Gegenkults ausweichen. In beiden Fällen war sie darüber hinaus zugleich energischen Versuchen der Ordnungsmacht zur totalen Terrain- und Symbolkontrolle ausgesetzt. Im Ergebnis kamen die Initiatoren des Baudin-Denkmals, das im weitesten Sinne der Revolutionserinnerung zuzurechnen war, weil es den Zusammenbruch republikanischer Anfänge unter der rigiden Militanz des Staatsstreichs memorieren sollte, über die Berliner Initiative nicht hinaus, da die Denkmalsetzung in beiden Fällen verhindert wurde. Dies, obschon die französische Initiative zwanzig Jahre später als die preußische mit subtileren Kultmethoden arbeitete, indem sie geschickt das christlich-religiöse Totengedenken als Anknüpfungspunkt für ihre politische Agitation zu nutzen versuchte, um Popularitätseffekte für den 
politisch-oppositionellen Märtyrerkult abzuschöpfen und den Zugriff der staatlichen Ordnungsmacht auf das am Feiertag sakral besetzte Friedhofsterrain zu erschweren. Gleichwohl gelangten nicht nur die Initiatoren, sondern auch eine zunehmend weniger kujonierte liberale Presse, anders als dies für den Diskussionsstand vom März 1848 für Berlin gelten konnte, im Zusammenhang mit dem Pariser Baudin-Projekt von 1868 zu ungleich weiterreichenden programmatischen Grundaussagen: Die Nation konzipierten sie partizipatorisch, demokratisch und plural, im versuchten Denkmalkult erkannten sie eine Art Grundrecht auf rituelle Selbstbildstiftung und in der Opposition eine nicht zuletzt zur freien Gedächtnisstiftung befugte Institution. Dem Empereur wurde demgegenüber bestritten, Traditionsbildung auf dem Wege offiziöser Geschichtsklitterung und unter dem Vorzeichen einer eklektischen Siegergeschichte erzwingen zu können. Diachrone Ähnlichkeiten wiesen wiederum die Reaktionen der autoritären Herrschaftssysteme auf, sofern selbst das in der Liberalisierung begriffene Empire nicht anders als die Repräsentanten der Ordungsmacht in Berlin sich der ungebetenen Nationsdeutungen auf dem Wege der Kriminalisierung ihrer Verfechter zu entledigen versuchten und damit vorerst auch erfolgreich verfuhren. 